\title{
Iron versus ruthenium: clarifying the electronic differences between prototypical mixed-valence organometallic butadiyndiyl-bridged molecular wires
}

\author{
Simon Gückel, ${ }^{\mathrm{a}}$ Josef B. G. Gluyas, ${ }^{\mathrm{b}}$ Sarah El-Tarhuni, ${ }^{\mathrm{c}}$ Alexandre N. Sobolev, ${ }^{\text {b,d }}$ Mark W. \\ Whiteley, ${ }^{\mathrm{c}}$ Jean-Francois Halet, ${ }^{\mathrm{e}}$ Claude Lapinte, ${ }^{\mathrm{e}}$ Martin Kaupp, ${ }^{* \mathrm{a}}$ and Paul J. Low ${ }^{\text {b }}$
}

${ }^{a}$ Institut für Chemie, Technische Universität Berlin, Sekr. C7, Strasse des 17. Juni 135, 10623 Berlin, Germany,

${ }^{\mathrm{b}}$ School of Molecular Sciences, University of Western Australia, 35 Stirling Highway, Crawley, Perth 6009, Australia,

${ }^{c}$ School of Chemistry, University of Manchester, Oxford Rd, Manchester, M13 9PL, UK,

${ }^{\mathrm{d}}$ Centre for Microscopy Characterisation and Analysis, University of Western Australia, 35 Stirling Highway, Crawley, Perth 6009, Australia

${ }^{e}$ Université Rennes, CNRS, ISCR - UMR 6226, F-35000 Rennes, France

\author{
"To whom correspondence should be addressed. \\ PJL - Phone: +61(8)6488-3045. E-mail: paul.low@uwa.edu.au. \\ MK - Phone: +49 30314 79682. E-mail: martin.kaupp@tu-berlin.de
}

\begin{abstract}
The electronic structures of the prototypical bimetallic buta-1,3-diyn-1,4-diylbridged radical cation complexes $\left[\left\{\mathrm{M}(\mathrm{dppe}) \mathrm{Cp}^{\prime}\right\}_{2}(\mu-\mathrm{C} \equiv \mathrm{CC} \equiv \mathrm{C})\right]^{+}\left(\mathrm{M}=\mathrm{Fe}, \mathrm{Cp}^{\prime}=\mathrm{Cp} *\right.$ (1a), $\left.\mathrm{Cp}(\mathbf{1 b}) ; \mathrm{M}=\mathrm{Ru}, \mathrm{Cp}^{\prime}=\mathrm{Cp}^{*}(\mathbf{2 a}), \mathrm{Cp}(\mathbf{2 b})\right)$ have been (re-)investigated using a combination of UV-vis-NIR and IR spectroelectrochemistry, and quantum chemical calculations based on both dispersion-corrected global (BLYP35-D3) and local (Lh-SsirPW92-D3) hybrid functionals. Following analysis of new and existing data, including the IR-active $v(C \equiv C)$ bands, the iron compounds $[\mathbf{1}]^{+}$are re-classified as valence-trapped (Robin and Day Class II) mixed-valence complexes, in contrast to the ruthenium complexes $[2]^{+}$, which are delocalized (Robin and Day Class III) systems. All members of the series exist as a thermally populated distribution of conformers in solution, and the overlapping spectroscopic profiles make the accurate extraction of the parameters necessary for the analysis of $[1]^{+}$and $[2]^{+}$within the framework of the Marcus-Hush model extremely challenging. Analysis of the spin-density distributions from a range of conformational minima provides an alternative representation of
\end{abstract}


the degree of charge localization, and a comparison between members of the series is presented.

\section{Introduction}

The syntheses, redox properties, molecular and electronic structures of metal complexes bearing linear, "all-carbon" ligands, $\left[\left\{\mathrm{L}_{\mathrm{m}} \mathrm{M}\right\}\left(\mu-\mathrm{C}_{4}\right)\left\{\mathrm{ML}_{\mathrm{m}}\right\}\right]^{\mathrm{n}+}$ have been widely investigated since the first examples were synthesized in the mid 1970s. ${ }^{1}$ Among these investigations, the elucidation of the structure of the carbon-ligand and nature of the 'mixed-valence' derivatives $(n=1)$ as a function of the metal, M, and supporting ligands, $\mathrm{L}_{\mathrm{m}}$, have been topics of considerable interest. ${ }^{2-22}$ Four of the early examples of $\left[\left\{L_{m} M\right\}(\mu-C \equiv C C \equiv C)\left\{M L_{m}\right\}\right]^{+}$ complexes, specifically $\left[\{\mathrm{Cp} *(\mathrm{dppe}) \mathrm{Fe}\}(\mu-\mathrm{C} \equiv \mathrm{CC} \equiv \mathrm{C})\left\{\mathrm{Fe}(\mathrm{dppe}) \mathrm{Cp}^{*}\right\}\right]^{+}\left([\mathbf{1 a}]^{+}\right)($Chart 1$),^{2-3}$ $\left[\{\mathrm{Cp} *(\mathrm{dppe}) \mathrm{Ru}\}(\mu-\mathrm{C} \equiv \mathrm{CC} \equiv \mathrm{C})\left\{\mathrm{Ru}(\mathrm{dppe}) \mathrm{Cp}^{*}\right\}\right]^{+}\left([\mathbf{2 a}]^{+}\right)(\mathrm{Chart} 1),{ }^{10} \quad\left[\left\{\mathrm{Cp}\left(\mathrm{PPh}_{3}\right)_{2} \mathrm{Ru}\right\}(\mu-\right.$ $\left.\mathrm{C} \equiv \mathrm{CC} \equiv \mathrm{C})\left\{\mathrm{Ru}\left(\mathrm{PPh}_{3}\right)_{2} \mathrm{Cp}\right\}\right]^{+9}$ and $\left[\left\{\mathrm{Cp} *(\mathrm{NO})\left(\mathrm{PPh}_{3}\right) \operatorname{Re}\right\}(\mu-\mathrm{C} \equiv \mathrm{CC} \equiv \mathrm{C})\left\{\operatorname{Re}\left(\mathrm{PPh}_{3}\right)(\mathrm{NO}) \mathrm{Cp} *\right\}\right]^{+6}$, ${ }^{23}$ have become established as benchmark examples of highly delocalized or Class III mixedvalence complexes. Each complex is comprised of a buta-1,3-diyn-1,4-diyl fragment terminated by half-sandwich, $d^{6}$ metal fragments, and exhibits characteristic $v(C \equiv C)$ and NIR spectra. Whilst the IR spectra provide information concerning the formal bond order and a valence-bond description of the $\mathrm{C}_{4}$ ligand (augmented by information concerning the electron density at the metal from the $v(\mathrm{NO})$ band in the case of $\left[\left\{\mathrm{Cp} *(\mathrm{NO})\left(\mathrm{PPh}_{3}\right) \operatorname{Re}\right\}(\mu-\right.$ $\left.\left.\mathrm{C} \equiv \mathrm{CC} \equiv \mathrm{C})\left\{\operatorname{Re}\left(\mathrm{PPh}_{3}\right)(\mathrm{NO}) \mathrm{Cp}^{*}\right\}\right]^{+}\right)$, analysis of the NIR band envelopes found in the $\sim 5000$ $15000 \mathrm{~cm}^{-1}$ region within the framework of Marcus Hush theory, supported by quantumchemical calculations using HF or standard global hybrid functionals (B3LYP), were used to provide information concerning electronic structure in these earlier works. ${ }^{5-7,9,11}$

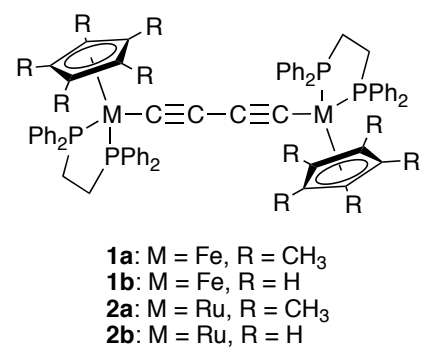

Chart 1. The bimetallic half-sandwich buta-1,3-diyn-1,4-diyl derived complexes under discussion. 
Recent re-investigations of the bimetallic ruthenium complex 2a (Chart 1), supported by analysis of closely related complexes including $[\{\mathrm{Cp}(\mathrm{dppe}) \mathrm{Ru}\}(\mu-\mathrm{C} \equiv \mathrm{CC} \equiv \mathrm{C})\{\mathrm{Ru}(\mathrm{dppe}) \mathrm{Cp}\}]$ (2b) (Chart 1), have shown that a more complete analysis of these systems requires explicit consideration of thermal populations of conformers that differ through rotation of one halfsandwich fragment relative to the other around the $\mathrm{Ru}-\mathrm{C} \equiv \mathrm{C}$ bond and hence offer different orbital overlaps over the $\mathrm{RuC}_{4} \mathrm{Ru}$ chain. ${ }^{14}{ }^{16}$ Conformational isomers have also been detected in ${ }^{31} \mathrm{P}$ NMR spectra of the iron complex 1a, with the rotational barrier determined to be some $28.2 \mathrm{~kJ}(6.74 \mathrm{kcal}) \mathrm{mol}^{-1} .^{24}$ The stability of the different rotamers, the thermal population of which will be important to the observed spectroscopic properties of solutions of the complex, are likely influenced by a combination of both steric and electronic interactions between the $\mathrm{Fe}($ dppe)Cp* fragments. On the basis of these observations we were drawn to re-examine the electronic structure and the electronic and vibrational spectroscopic data of $\left[\{\mathrm{Cp} *(\mathrm{dppe}) \mathrm{Fe}\}(\mu-\mathrm{C} \equiv \mathrm{CC} \equiv \mathrm{C})\left\{\mathrm{Fe}(\mathrm{dppe}) \mathrm{Cp}^{*}\right\}\right]^{+}\left([\mathbf{1 a}]^{+}\right)$, and the closely related species $[\{\mathrm{Cp}(\mathrm{dppe}) \mathrm{Fe}\}(\mu-\mathrm{C} \equiv \mathrm{CC} \equiv \mathrm{C})\{\mathrm{Fe}(\mathrm{dppe}) \mathrm{Cp}\}]^{+}\left([\mathbf{1 b}]^{+}\right)$(Chart 1) using specially constructed global and new local hybrid density functionals. The new analysis allows us to assign key spectroscopic features and to (re-)classify $[\mathbf{1 a}, \mathbf{b}]^{+}$in terms of a ground state population distribution that features many minima with significantly polarized ('localized') electronic structures. This significant ground state polarization in the population of the iron systems affords a clear contrast between the iron and ruthenium homologues. These studies further highlight the difficulty in applying conventional methods of analysis based on the MarcusHush theory to conformationally fluxional 'mixed-valence' systems of low symmetry.

\section{Results and Discussion}

The compound $[\{\mathrm{Cp}(\mathrm{dppe}) \mathrm{Fe}\}(\mu-\mathrm{C} \equiv \mathrm{CC} \equiv \mathrm{C})\{\mathrm{Fe}(\mathrm{dppe}) \mathrm{Cp}\}]^{+}$(1) $)$was prepared in the same two-step method as developed earlier for the preparation of the well-known complex $\left[\{\mathrm{Cp} *(\mathrm{dppe}) \mathrm{Fe}\}(\mu-\mathrm{C} \equiv \mathrm{CC} \equiv \mathrm{C})\left\{\mathrm{Fe}(\mathrm{dppe}) \mathrm{Cp}^{*}\right\}\right]^{+} \quad$ (1a), through a sequence of reactions involving initial oxidation of $\mathrm{Fe}(\mathrm{C} \equiv \mathrm{CH})(\mathrm{dppe}) \mathrm{Cp}$ to give the radical cation $[\mathrm{Fe}(\mathrm{C} \equiv \mathrm{CH})(\mathrm{dppe}) \mathrm{Cp}]^{+}$and homo-dimerization to give the bis(vinylidene) $\left[\{\mathrm{Fe}(\mathrm{dppe}) \mathrm{Cp}\}_{2}(\mu-\right.$ $\mathrm{C}=\mathrm{C}(\mathrm{H}) \mathrm{C}(\mathrm{H})=\mathrm{C})]^{2+}, 25$ followed by deprotonation. ${ }^{3}$ Multinuclear NMR spectra for the butadiyndiyl complex $\mathbf{1 b}$ were obtained at room temperature in the presence of a trace of $\mathrm{CoCp}_{2}$ to prevent accumulation of $\mathrm{Fe}(\mathrm{III})$ species by aerial oxidation; this procedure is an alternative to the low-temperature protocol employed for the equivalent characterization of 1a. ${ }^{3}$ In the ${ }^{13} \mathrm{C}\left\{{ }^{1} \mathrm{H}\right\}$ NMR spectrum, the quaternary carbons of the $\mathrm{C}_{4}$ bridge were observed at 
$\delta 110.2\left(\mathrm{C}_{\beta}\right)$ and $\delta 88.9\left(\mathrm{t}, J_{\mathrm{C}-\mathrm{P}}=44 \mathrm{~Hz}\right)$; the high-field shift of $\mathrm{C}_{\alpha}$ by comparison with related monometallic alkynyl complexes $[\mathrm{Fe}(\mathrm{C} \equiv \mathrm{CR})(\mathrm{dppe}) \mathrm{Cp}]$ is also a feature of the analogous $\mathrm{Fe}\left(\right.$ dppe)Cp* system. The room-temperature ${ }^{31} \mathrm{P}\left\{{ }^{1} \mathrm{H}\right\}$ NMR spectrum of $\mathbf{1 b}$ exhibits a singlet resonance at $\delta$ 105.0. Crystallographic characterization of $\mathbf{1 b}$ (Figure S1) confirmed the butadiyndiyl form of the $\mathrm{C}_{4}$ bridge $(\mathrm{Fe}-\mathrm{C}(\alpha)$ 1.884(3) $\AA, \mathrm{C}(\alpha)-\mathrm{C}(\beta) 1.220(4) \AA, \mathrm{C}(\beta)-\mathrm{C}(\gamma)$ $1.373(4) \AA, \mathrm{C}(\gamma)-\mathrm{Fe} 1.889(3) \AA$ ) , typical of complexes of this type. ${ }^{5,11,26-30}$

As noted above, much of the interest in butadiyndiyl-bridged complexes stems from the changes in molecular and electronic structure that occur as a function of redox state. The electrochemical responses of many complexes of the general formula $\left\{\left(\eta-\mathrm{C}_{5} \mathrm{R}_{5}\right)(\mathrm{PP}) \mathrm{M}\right\}(\mu-$ $\mathrm{C} \equiv \mathrm{CC} \equiv \mathrm{C})\left\{\mathrm{M}^{\prime}(\mathrm{PP})^{\prime}\left(\eta-\mathrm{C}_{5} \mathrm{R}^{\prime}{ }_{5}\right)\right\}(\mathrm{M}=\mathrm{Fe}, \mathrm{Ru})$ have been reported and discussed on previous occasions. ${ }^{1,5}$ In general the complexes undergo three $(\mathrm{M}=\mathrm{Fe}){ }^{4}$ or four $(\mathrm{M}=\mathrm{Ru})^{8-10,14,16}$ oxidation processes within the electrochemical window of common solvents. The new compound $1 \mathbf{b}$ displays three redox processes in $0.1 \mathrm{M} \mathrm{NBu}_{4} \mathrm{PF}_{6} / \mathrm{CH}_{2} \mathrm{Cl}_{2}$ electrolyte at a $\mathrm{Pt}$ electrode $\left(-0.94,-0.28,+0.53 \mathrm{~V}\right.$ vs $\mathrm{Fc} / \mathrm{Fc}^{+}=0.00 \mathrm{~V}, \mathrm{Fc}^{*} / \mathrm{Fc}^{*+}=-0.55 \mathrm{~V}$ Figure S2), which are as reversible as the internal decamethylferrocene/decamethylferrocinium reference couple, paralleling the behavior of the $\mathrm{Cp}^{*}$ analogue 1a $(-1.14,-0.42,+0.49 \mathrm{~V})$ under identical conditions. Comparison of these data reveals trends which support and extend concepts developed in earlier studies of various members of the $\left\{\left(\eta-C_{5} R_{5}\right)(\right.$ dppe $\left.) M\right\}(\mu$ $\mathrm{C} \equiv \mathrm{CC} \equiv \mathrm{C})\left\{\mathrm{M}(\mathrm{dppe})\left(\eta-\mathrm{C}_{5} \mathrm{R}_{5}\right)\right\}$ series $(\mathrm{M}=\mathrm{Fe}, \mathrm{Ru} ; \mathrm{R}=\mathrm{Me}, \mathrm{H}){ }^{11}$ Firstly, the formal substitution of $\mathrm{Cp}(\mathrm{R}=\mathrm{H})$ for $\mathrm{Cp} *(\mathrm{R}=\mathrm{Me})$ causes a more significant shift to less positive (more negative ) potentials of the first $\left(\Delta \mathrm{E}_{1}=-0.20 \mathrm{~V}\right)$ and second $\left(\Delta \mathrm{E}_{2}=-0.14 \mathrm{~V}\right)$ redox processes than the third $\left(\Delta \mathrm{E}_{3}=-0.04 \mathrm{~V}\right)$. Secondly, the third redox potentials are almost independent of the nature of supporting cyclopentadienyl ligand $\left(\mathrm{E}_{3}=+0.95 \mathrm{~V}(\mathbf{1 a}),+0.99 \mathrm{~V}\right.$ (1b)). This is entirely consistent with the notion that the latter redox events are more carbonchain in character, ${ }^{4,9}$ which is supported here by the observation of a low-frequency $v(\mathrm{CCCC})$ band by in situ spectroelectrochemistry for $[\mathbf{1 b}]^{3+}\left(1684 \mathrm{~cm}^{-1}\right)$.

Guided by the electrochemical results, the synthesis of $[\mathbf{1 b}]^{\mathrm{n}+}(\mathrm{n}=1$ or 2$)$ by chemical oxidation with ferrocenium hexafluorophosphate was investigated. Oxidation of a cooled $\left(0{ }^{\circ} \mathrm{C}\right)$ dichloromethane solution of $\mathbf{1 b}$ with two equivalents of ferrocenium hexafluorophosphate resulted in a rapid color change from orange to deep green, and the dication $[\mathbf{1 b}]\left[\mathrm{PF}_{6}\right]_{2}$ was subsequently isolated as a deep green solid. The monocation 
$[\mathbf{1 b}]\left[\mathrm{PF}_{6}\right]$ could also be obtained by ferrocenium oxidation of $\mathbf{1 b}$, but the preferred protocol involves the comproportionation reaction of equimolar quantities of $[\mathbf{1 b}]\left[\mathrm{PF}_{6}\right]_{2}$ and $\mathbf{1 b}$ in $\mathrm{CH}_{2} \mathrm{Cl}_{2}$ which led to the isolation of $[\mathbf{1 b}]\left[\mathrm{PF}_{6}\right]$ as a black-green solid. The oxidized complexes $[\mathbf{1 b}]^{\mathrm{n}+}(\mathrm{n}=1$ or 2$)$ were characterized by IR spectroscopy, mass spectrometry and microanalytical data. IR data in the $v(\mathrm{C} \equiv \mathrm{C})$ stretching region recorded on isolated samples of $[\mathbf{1 b}]^{\mathrm{n}+}$ fully concur with the data obtained from spectroelectrochemical investigations (see below). Microanalytical data indicate the inclusion of some dichloromethane of crystallization in both $[\mathbf{1 b}]\left[\mathrm{PF}_{6}\right]$ and $[\mathbf{1 b}]\left[\mathrm{PF}_{6}\right]_{2}$; a similar observation was made for the $\mathrm{Cp}^{*}$ analogue $[\mathbf{1} \mathbf{a}]\left[\mathrm{PF}_{6}\right] .^{3}$

Samples of both $[\mathbf{1 b}]\left(\mathrm{PF}_{6}\right)$ and $[\mathbf{1 b}]\left(\mathrm{PF}_{6}\right)_{2}$ decomposed slowly in air to give $[\mathrm{Fe}(\mathrm{CO})(\mathrm{dppe}) \mathrm{Cp}]\left(\mathrm{PF}_{6}\right)$, characterized by a strong $v(\mathrm{CO})$ band $\left(1978 \mathrm{~cm}^{-1}\left(\mathrm{CH}_{2} \mathrm{Cl}_{2}\right) ; 1970\right.$ $\left.\mathrm{cm}^{-1}(\mathrm{ATR})\right)$ and molecular ion at $\mathrm{m} / z($ MALDI-MS $)=547 \mathrm{amu}$. An authentic sample of the carbonyl cation $[\mathrm{Fe}(\mathrm{CO})(\mathrm{dppe}) \mathrm{Cp}]^{+31-32}$ was independently synthesized and isolated as the $\mathrm{BPh}_{4}^{-}$salt, and shown to exhibit identical IR spectroscopic $\left(v(\mathrm{CO})=1979 \mathrm{~cm}^{-1}\left(\mathrm{CH}_{2} \mathrm{Cl}_{2}\right)\right.$, $1970 \mathrm{~cm}^{-1}$ (ATR)) and mass spectrometric properties to those of the decomposition product from $[\mathbf{1 b}]\left(\mathrm{PF}_{6}\right)_{\mathrm{n}}$. It has also been shown that in the $\mathrm{Cp}^{*}$ series, compounds with general formula $\left[\mathrm{Fe}(\mathrm{C} \equiv \mathrm{CR})(\mathrm{dppe}) \mathrm{Cp}^{*}\right]^{+}$react readily with $\mathrm{O}_{2}$ to form the analogous carbonyl cation $\left[\mathrm{Fe}(\mathrm{CO})(\mathrm{dppe}) \mathrm{Cp}^{*}\right]^{+}{ }^{33}$ Therefore, to avoid complications arising from aerial decomposition of the chemically prepared and isolated redox products, NIR and IR spectra of the redox series $[\mathbf{1} \mathbf{a}]^{\mathrm{n}+}$ and $[\mathbf{1 b}]^{\mathrm{n}+}(\mathrm{n}=0,1,2)$ were collected in a spectroelectrochemical cell of Hartl design (Table S1). ${ }^{34}$ Strictly anaerobic conditions were maintained during the experiments by performing sample preparation, filling and sealing the cell in a dinitrogen-filled dry glovebox using rigorously dried and degassed solvents. Failure to observe these precautions led to observation of the characteristic $\left[\mathrm{Fe}(\mathrm{CO})(\mathrm{dppe}) \mathrm{Cp}^{\prime}\right]^{+} v(\mathrm{CO})$ bands, indicating sample decomposition.

Before commencing a description of the experimental spectra, it is helpful to first note the vibrational modes of a model buta-1,3-diyne. The two highest frequency modes will arise from the 'symmetric' and 'asymmetric' stretches of the four-carbon fragment; the atomic displacements that correspond to these modes are shown schematically in Figure 1. For a centrosymmetric molecule featuring the linear $\mathrm{C}_{4}$ fragment, $\mathrm{Y}-\mathrm{C} \equiv \mathrm{CC} \equiv \mathrm{C}-\mathrm{Y}$, the symmetric stretch will be IR inactive, the asymmetric IR active. In contrast, in an asymmetrically 
substituted derivative, $\mathrm{X}-\mathrm{C} \equiv \mathrm{CC} \equiv \mathrm{C}-\mathrm{Y}$, both bands will be IR active. Thus for $\mathrm{HC} \equiv \mathrm{CC} \equiv \mathrm{CH}$, a single (unscaled) IR-active, but low-intensity $v(\mathrm{C} \equiv \mathrm{CC} \equiv \mathrm{C})$ harmonic vibrational frequency is calculated (BLYP35-D3/def2-SVP) at $2158 \mathrm{~cm}^{-1}$, whilst $\mathrm{HC} \equiv \mathrm{CC} \equiv \mathrm{CPh}$ gave IR active $v(\mathrm{C} \equiv \mathrm{CC} \equiv \mathrm{C})$ modes at 2211 and $2376 \mathrm{~cm}^{-1}$ at the same level of theory.
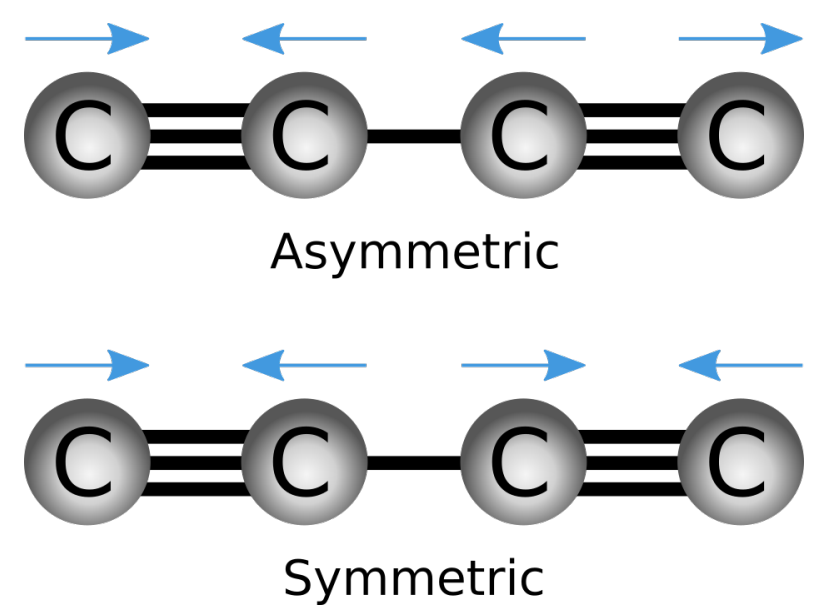

Figure 1. A schematic representation of the $v(C \equiv C C \equiv C)$ modes in buta-1,3-diyne.

In the IR spectra of $\mathbf{1 a}$ and $\mathbf{1 b}$ the 'asymmetric' $v(C \equiv C C \equiv C)$ stretch is observed near 1955 (1a) $\left\{\right.$ Coat:2003hj\} or 1950 (1b) $\mathrm{cm}^{-1}$ with discernable shoulders to the low (1a) or high (1b) frequency side of the band (Figure 2). As has been discussed elsewhere for related ruthenium butadiyndiyl complexes, ${ }^{14,16}$ these shoulders are characteristic of a distribution of conformers in solution; such rotamers have also been detected by low-temperature ${ }^{31} \mathrm{P}$ NMR spectroscopy in the case of $\mathbf{1} \mathbf{a}^{24}$ The formally forbidden symmetric $v(\mathrm{C} \equiv \mathrm{CC} \equiv \mathrm{C})$ band has been detected as a very weak feature near $2103 \mathrm{~cm}^{-1}$ (Figure S3) in the IR spectrum of 1a, likely due to symmetry breaking from rotation of the half-sandwich fragments around the long molecular axis. $^{24}$

The 'mixed-valence' monocations $[\mathbf{1 a}]^{+}$and $[\mathbf{1 b}]^{+}$are characterized by two main vibrational features corresponding to the symmetric and asymmetric $v(\mathrm{C} \equiv \mathrm{CC} \equiv \mathrm{C})$ stretches at 1976 and $1880 \mathrm{~cm}^{-1}\left([\mathbf{1 a}]^{+}\right)$and 1979 and $1877 \mathrm{~cm}^{-1}\left([\mathbf{1 b}]^{+}\right)$, overlying a low-intensity electronic absorption band, and providing the first clear evidence of valence-localization in at least some of the conformations of these compounds on the IR timescale. Each main vibrational feature also exhibits shoulders to lower frequency, which point to additional conformational isomers in solution. Close scrutiny of the IR spectra of the isostructural ruthenium complexes 
$[\mathbf{2 a}]^{+}$and $[\mathbf{2 b}]^{+}$reveals a very weak band feature near $2000 \mathrm{~cm}^{-1}$ for the symmetric $v(\mathrm{C} \equiv \mathrm{CC} \equiv \mathrm{C})$ stretch in addition to the more prominent bands for the asymmetric $v(\mathrm{C} \equiv \mathrm{CC} \equiv \mathrm{C})$ stretch at $1860\left([\mathbf{2 a}]^{+}\right)$and $1859\left([\mathbf{2 b}]^{+}\right) \mathrm{cm}^{-1}$ (Figure 2, Figure S4). The apparent differences in the IR spectra of these formally mixed-valence mono-cations $[\mathbf{1} \mathbf{a}, \mathbf{b}]^{+}$and $[\mathbf{2 a}, \mathbf{b}]^{+}$can be summarized in terms of the intensity of the higher-frequency, broad 'symmetric' $v(C \equiv C C \equiv C)$ band (Figure 2). The significant IR activity of the 'symmetric' $v(\mathrm{C} \equiv \mathrm{CC} \equiv \mathrm{C})$ band in $[\mathbf{1} \mathbf{a}, \mathbf{b}]^{+}$ points strongly to a non-centrosymmetric structure (i.e. valence localization on the IR timescale) of these iron complexes, whilst the vanishingly small intensity of this vibration in $[\mathbf{2 a}, \mathbf{b}]^{+}$points to a more centrosymmetric (valence delocalized) structure for the ruthenium homologues.

This conclusion of a greater degree of localized (or Class II mixed-valence) character in the iron compounds is seemingly at odds with the greater separation of the first and second redox waves associated with the oxidation of $[\mathbf{1 a}]\left(\Delta \mathrm{E}_{1 / 2}=0.72 \mathrm{~V}\right)$ when compared with $[\mathbf{2} \mathbf{a}]\left(\Delta \mathrm{E}_{1 / 2}\right.$ $=0.65 \mathrm{~V})$ and hence larger comproportionation constant and thermodynamic stability of $[\mathbf{1} \mathbf{a}]^{+}$ $\left(\mathrm{K}_{\mathrm{C}}=1.6 \times 10^{12}\right)$ than $[\mathbf{2 a}]^{+}\left(\mathrm{K}_{\mathrm{C}}=9.7 \times 10^{10}\right)$. However, the results of a relatively recent analysis of the magnetic behavior of $[\mathbf{1} \mathbf{a}]\left[\mathrm{PF}_{6}\right]_{2}$ and $[\mathbf{2 a}]\left[\mathrm{PF}_{6}\right]_{2}$ and thermodynamic terms associated with the comproportionation equilibria give further insight, ${ }^{35}$ and together begin to draw the various earlier observations and those made here into a consistent picture. As discussed in various degree of detail in summaries published elsewhere, ${ }^{36-38}$ the thermodynamic stability of mixed-valence complexes, expressed as the free energy of comproportionation, $\Delta G_{\mathrm{C}}$, can be attributed to contributions from not only the 'resonance' effects that relate to the concepts of 'metal-metal coupling', but also from entropic, electrostatic, inductive, solvation, ion-pairing and magnetic terms. From the temperature dependence of the chemical shifts vs $1 / T$, a singlet-triplet energy gap of $\Delta G_{\mathrm{ST}}=-850 \mathrm{~cm}^{-1}$ was determined for $[\mathbf{2 a}]^{2+}$, which is very much greater than that found for $[\mathbf{1 a}]^{2+}\left(\Delta G_{\mathrm{ST}}=\right.$ $\left.-18 \mathrm{~cm}^{-1}\right)$. The greater stabilization of the (singlet) dication $[\mathbf{2 a}]^{2+}$ shifts the comproportionation equilibrium

$$
\begin{aligned}
& {\left[\left\{\mathrm{L}_{\mathrm{m}} \mathrm{M}\right\}(\mu-\mathrm{C} \equiv \mathrm{CC} \equiv \mathrm{C})\left\{\mathrm{ML}_{\mathrm{m}}\right\}\right]+\left[\left\{\mathrm{L}_{\mathrm{m}} \mathrm{M}\right\}(\mu-\mathrm{C} \equiv \mathrm{CC} \equiv \mathrm{C})\left\{\mathrm{ML}_{\mathrm{m}}\right\}\right]^{2+} \leftrightarrows} \\
& 2\left[\left\{\mathrm{~L}_{\mathrm{m}} \mathrm{M}\right\}(\mu-\mathrm{C} \equiv \mathrm{CC} \equiv \mathrm{C})\left\{\mathrm{ML}_{\mathrm{m}}\right\}\right]^{+}
\end{aligned}
$$


to the left, despite the greater resonance contribution calculated previously from the MarcusHush two-state model. ${ }^{35}$ In addition, whilst Mössbauer spectroscopic data from $[\mathbf{1 a}]^{+}$are consistent with a delocalized structure, ${ }^{3}$ Mössbauer operates on slower timescales (ca. $10^{-9} \mathrm{~s}$ ) than molecular vibrations observed by IR measurements (ca. $10^{-13} \mathrm{~s}$ ), suggesting a range for the possible electron transfer rate.

Further oxidation to the dications leads to another decrease in the frequencies of the symmetric and asymmetric stretches of the $\mathrm{C}_{4}$ bridge, with the symmetric band being almost IR silent and only detectable in the $\left[\mathrm{M}(\mathrm{dppe})\left(\eta-\mathrm{C}_{5} \mathrm{H}_{5}\right)\right]$ derived complexes as an extremely weak feature near $1880 \mathrm{~cm}^{-1}\left([\mathbf{1 b}]^{2+}\right)$ and $1860 \mathrm{~cm}^{-1}\left([\mathbf{2 b}]^{2+}\right)$ (Figure 2). The asymmetric stretch was observed more clearly as a weak to medium intensity band in the iron complexes at $1813\left([\mathbf{1 a}]^{2+}\right)$ and $1807\left([\mathbf{1 b}]^{2+}\right) \mathrm{cm}^{-1}$, close to those observed in the analogous ruthenium complexes $\left[\left\{\left(\eta-\mathrm{C}_{5} \mathrm{R}_{5}\right)(\mathrm{dppe}) \mathrm{Ru}\right\}(\mu-\mathrm{C}=\mathrm{C}=\mathrm{C}=\mathrm{C})\left\{\mathrm{Ru}(\mathrm{dppe})\left(\eta-\mathrm{C}_{5} \mathrm{R}_{5}\right)\right\}\right]\left(\mathrm{PF}_{6}\right)_{2} \quad(\mathrm{R}=\mathrm{Me}, 1770$ $\mathrm{cm}^{-1}\left([\mathbf{2} \mathbf{a}]^{2+}\right) ;{ }^{10,16} \mathrm{R}=\mathrm{H}, 1772 \mathrm{~cm}^{-1}\left([\mathbf{2} \mathbf{b}]^{2+}\right),{ }^{16}$ and taken as evidence for a significant cumulene contribution to the bridging $\mathrm{C}_{4}$ ligand structure. 

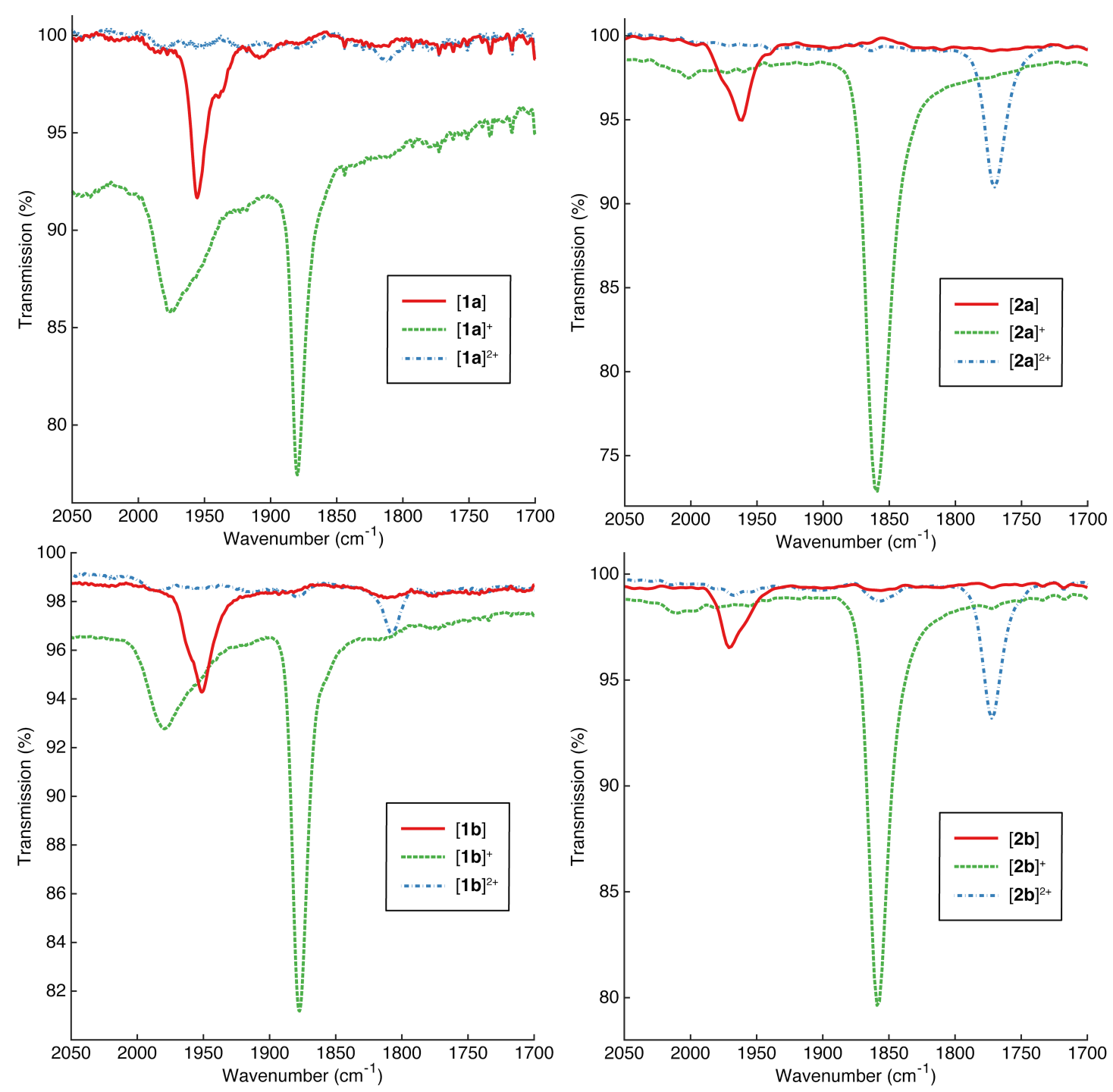

Figure 2. The $v(\mathrm{C} \equiv \mathrm{C})$ IR spectra of $[\mathbf{1} \mathbf{a}]^{\mathrm{n}+},[\mathbf{1 b}]^{\mathrm{n}+},[\mathbf{2} \mathbf{a}]^{\mathrm{n}+}$ and $[\mathbf{2} \mathbf{b}]^{\mathrm{n}+}(\mathrm{n}=0,1,2)$ in $0.1 \mathrm{M}$ $\mathrm{NBu}_{4} \mathrm{PF}_{6} / \mathrm{CH}_{2} \mathrm{Cl}_{2}$.

The electronic structures of $[\mathbf{2} \mathbf{a}, \mathbf{b}]^{+}$have been explored recently using computations with the global BLYP35-D3 hybrid functional ${ }^{39-41}$ for a range of thermally accessible molecular conformations that differ through the relative positions of the half-sandwich fragments across the $\mathrm{C}_{4}$ bridge (Figure 3 ). ${ }^{14,16}$ In each conformer the compounds offer highly delocalized electronic structures and may be described as Class III mixed-valence complexes, albeit with a small polarization of electron density in the 'perpendicular' conformer. 


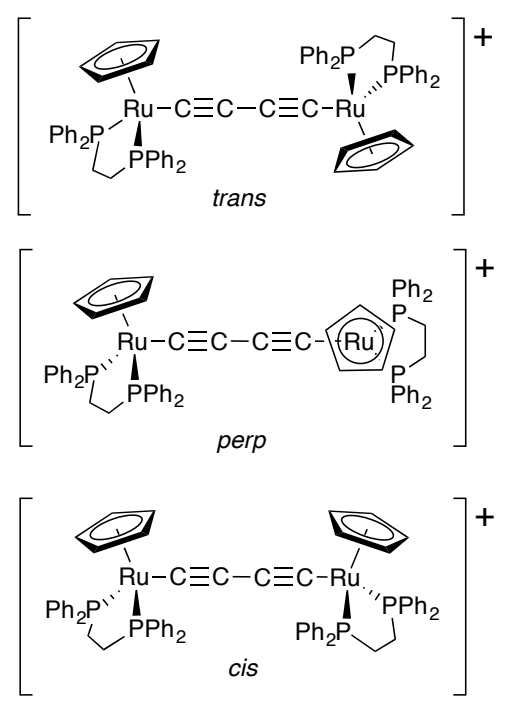

Figure 3. Schematic representations of three low-lying minima of $[\mathbf{2} \mathbf{b}]^{+}$for illustrative purposes.

It is likely that the small symmetry breaking arising from the relative orientations of the $\mathrm{Ru}(\mathrm{dppe}) \mathrm{Cp}^{\prime}$ fragments in the perp forms is responsible for the weak symmetric $v(\mathrm{C} \equiv \mathrm{CC} \equiv \mathrm{C})$ band observed in the spectra of $[\mathbf{2 a}, \mathbf{b}]^{+}$near $2000 \mathrm{~cm}^{-1}$ (Figure 2). ${ }^{16}$ Consistent with the lack of rotational dynamics in solid samples, the ATR spectrum of [2a]PF 6 shows a more prominent signal corresponding to the symmetric stretch at $1992 \mathrm{~cm}^{-1}$ with the asymmetric stretch at $1854 \mathrm{~cm}^{-1}$ (Figure S4). A significant increase in the relative intensity of the symmetric $v(\mathrm{C} \equiv \mathrm{CC} \equiv \mathrm{C})$ feature relative to that seen in solution is also apparent in solid-state spectra of $[\mathbf{1 a}] \mathrm{PF}_{6}$ (Figure S4). However, it seems unlikely that conformational factors alone can satisfactorily explain the different intensities of the symmetric IR $v(C \equiv C C \equiv C)$ band, when comparing the iron and ruthenium species.

To better explain the IR spectra of $[\mathbf{1 a}, \mathbf{b}]^{+}$, computations at BLYP35-D3/def2-SVP level were carried out. We note in passing that the $35 \%$ exact-exchange admixture of BLYP35-D3 has been found to provide a good compromise for modeling both localized and delocalized organic, inorganic and organometallic mixed-valence systems. ${ }^{42}$ A conformational scan for the computationally less intensive compound $[\mathbf{1 b}]^{+}$was undertaken, with sample points for initial geometry optimization of $[\mathbf{1 a}]^{+}$being drawn from those identified for structurally similar $[\mathbf{2 a}]^{+}{ }^{16}$ Geometry optimizations were carried out giving four energetically similar minima which are denoted by the torsion angle P-Fe...Fe-P $\left(\Omega^{\circ}\right)$ for $[\mathbf{1 a}]^{+}(\Omega=55,94,110$, 
$\left.144^{\circ}\right)$, and five for $[\mathbf{1 b}]^{+}\left(\Omega=36,51,86,135,147^{\circ}\right)$ (Table 1, Figure S5). The conformational distribution and dihedrals of these minima are comparable to the respective ruthenium homologues $[\mathbf{2 a}]^{+}$(Figure S6) and $[\mathbf{2 b}]^{+}$(Figure S7). The lowest-energy structures of [1a $]^{+}$ and $[\mathbf{2} \mathbf{a}]^{+}$exhibit $\Omega$ close to $50^{\circ}\left(55^{\circ}\right.$ and $51^{\circ}$, respectively), while $[\mathbf{1 b}]^{+}$and $[\mathbf{2 b}]^{+}$with the bulkier $\mathrm{Cp}^{*}$ ligands have values close to $30^{\circ}\left(36^{\circ}\right.$ and $33^{\circ}$, respectively). As discussed elsewhere for the ruthenium species, ${ }^{16}$ dispersion interactions between the two ligand spheres are responsible for these preferences, and are strongest for the lowest-energy minima. The observation of the critical role that dispersion plays in these structures is intriguing, especially in light of the IR spectra of the related compound $[\{\mathrm{Cp}(\operatorname{dippe}) \mathrm{Fe}\}(\mu-$ $\mathrm{C} \equiv \mathrm{CC} \equiv \mathrm{C})\{\mathrm{Fe}($ dippe $) \mathrm{Cp}\}]^{+} \quad\left([\mathbf{1 c}]^{+}\right)$featuring the smaller, alkyl diphospine, diisopropylphosphinoethane (dippe). In solid state as a Nujol mull, the IR spectrum of $[\mathbf{1 c}] \mathrm{PF}_{6}$ exhibits a similar pattern of two $v(\mathrm{C} \equiv \mathrm{C})$ bands $\left(1977,1879 \mathrm{~cm}^{-1}\right)$ as observed for $[\mathbf{1 a}]^{+}$and $[\mathbf{1 b}]^{+}$, whilst in $\mathrm{CH}_{2} \mathrm{Cl}_{2}$ solution only a single, asymmetric stretch $v(\mathrm{C} \equiv \mathrm{C})$ band is observed at $1878 \mathrm{~cm}^{-1} .^{4}$ It is interesting to speculate on the role that the steric and intramolecular electronic $(\mathrm{CH}-\pi)$ interactions play in influencing the conformational distribution in the entire family of compounds $\left[\left\{L_{m} M\right\}(\mu-C \equiv C C \equiv C)\left\{M L_{m}\right\}\right]^{\text {n+ }}$, although further explicit discussion of this point must await a more comprehensive study of analogues of $[\mathbf{1 c}]^{\mathrm{n+}}$.

Earlier computations on truncated-ligand models for $[\mathbf{1} \mathbf{a}]^{+7,11}$ gave delocalized structures and spin-density distributions. However, the low exact-exchange admixture (20\%) of B3LYP is known to clearly over-delocalize Class II systems. ${ }^{42}$ To provide a lower localization limit to the present computations using full ligand models with dispersion corrections, we have also optimized several minima of $[\mathbf{1 a}]^{+}$and $[\mathbf{1 b}]^{+}$at B3LYP-D3/def2-SVP level (Table S2, Table S3a). Interestingly, while the B3LYP results for $[\mathbf{1 b}]^{+}$indeed are close to a fully delocalized situation, clear symmetry breaking is still found for $[\mathbf{1 a}]^{+}$even at this computational level known to be biased towards delocalized situations. This provides additional support to a Class II description, in particular for the somewhat more weakly coupled [1a $]^{+}$. Examination of the optimized structures of both $[\mathbf{1 a}]^{+}$and $[\mathbf{1 b}]^{+}$at the more suitable (even if possibly somewhat too localized) BLYP35-D3 level of theory reveals significant structural differences at the iron centers, with the average $\mathrm{Fe}(2)$-P distances ca. $0.05 \AA$ longer than those at $\mathrm{Fe}(1)$ (Table S2). There is a concomitant decrease in $\mathrm{Fe}(2)-\mathrm{C} \delta$ distances relative to $\mathrm{Fe}(1)-\mathrm{C} \alpha$ of ca. $0.015 \AA\left([\mathbf{1 a}]^{+}\right)$and ca. $0.03 \AA\left([\mathbf{1 b}]^{+}\right)$. This points clearly to localized oxidation at $\mathrm{Fe}(2)$. As a result of this polarized structure, vibrational bands arising from both 'symmetric' and 
'asymmetric' atomic displacements in the $\mathrm{C} \equiv \mathrm{CC} \equiv \mathrm{C}$ chain have significant oscillator strength or intensity in all of the minima explored, giving rise to bands that fall between $1969-1987$ $\mathrm{cm}^{-1}$ and $1882-1891 \mathrm{~cm}^{-1}\left([\mathbf{1} \mathbf{a}]^{+}\right)$or between $1952-1971 \mathrm{~cm}^{-1}$ and $1875-1883 \mathrm{~cm}^{-1}$ $\left([\mathbf{1 b}]^{+}\right)$. The calculations not only reproduce the frequencies of the experimentally observed two-band pattern for $[\mathbf{1} \mathbf{a}, \mathbf{b}]^{+}$(Figure 2) but, given the greater spread of vibrational frequencies for the symmetric vibrational mode as a function of conformation (Table 1), also reproduce the shape of the bands and the general appearance of the spectra (Figure 2). However, the calculations do not reproduce the relative intensities of the $v(C \equiv C C \equiv C)$ bands observed experimentally due to the overestimation of charge-localization by BLYP35-D3. 
Table 1: Computed harmonic vibrational frequencies for different conformers of [1a] ${ }^{+}$ and $[\mathbf{1 b}]^{+}$(BLYP35-D3/def2-SVP). $v_{1}, v_{2}$ denote the symmetric and asymmetric alkynyl stretch, respectively. The computed frequencies are scaled by a factor of $0.895 .^{43}$

\begin{tabular}{|c|c|c|c|c|c|c|c|c|c|}
\hline \multicolumn{5}{|c|}{$[\mathbf{1 a}]^{+}$} & \multicolumn{5}{|c|}{$[\mathbf{1 b}]^{+}$} \\
\hline$\Omega$ & \multicolumn{4}{|c|}{ IR frequencies } & $\Omega$ & \multicolumn{4}{|c|}{ IR frequencies } \\
\hline$\left[{ }^{\circ}\right]$ & $\begin{array}{l}v_{1} / \\
\mathrm{cm}^{-1}\end{array}$ & int. & $\begin{array}{l}v_{2} / \\
\mathrm{cm}^{-1}\end{array}$ & int. & {$\left[{ }^{\circ}\right]$} & $\begin{array}{l}v_{1} / \\
\mathrm{cm}^{-1}\end{array}$ & int. & $\begin{array}{l}v_{2} / \\
\mathrm{cm}^{-1}\end{array}$ & int. \\
\hline & & & & & 36 & 1953 & 4376 & 1875 & 168 \\
\hline 55 & 1980 & 3451 & 1888 & 41 & 51 & 1955 & 4425 & 1876 & 333 \\
\hline 94 & 1987 & 3129 & 1891 & 44 & 86 & 1971 & 3709 & 1883 & 179 \\
\hline 110 & 1985 & 3126 & 1890 & 22 & 135 & 1955 & 4635 & 1876 & 258 \\
\hline 144 & 1969 & 3808 & 1882 & 51 & 147 & 1952 & 4999 & 1876 & 321 \\
\hline $\operatorname{Exp}$ & 1976 & & 1880 & & & 1980 & & 1877 & \\
\hline
\end{tabular}

Whilst the localized BLYP35-D3 structures (Table S2) satisfactorily explain the appearance of the IR spectra, the $S^{2}$ expectation values (ca. 0.82 compared to the nominal 0.75 for a doublet state) indicate significant spin contamination, and analysis of the spin-density population shows excess spin polarization (in part with appreciably negative spin densities) along the $\mathrm{C}_{4}$-bridge. This contrasts with the analogous ruthenium complexes [2a,b], where little spin contamination is observed at the same computational level (Table 2). In order to provide a better description of the spin-density distribution, and in particular better electronic excitation spectra in TDDFT calculations (see below), single point calculations using the local hybrid functional Lh-SsirPW92-D3 ${ }^{44}$ were performed (with D3-type dispersion corrections), using a recent efficient implementation. ${ }^{45-46}$

Related local hybrids, which in contrast to BLYP35 or B3LYP exhibit position-dependent rather than constant exact-exchange admixture, have recently been shown to provide a good description of both localized and delocalized mixed-valence systems, ${ }^{47}$ while reducing the spin contamination compared to "global" hybrids with high exact exchange, such as BLYP35. The structures were not optimized with local hybrids, as the higher computational demand of the current gradient implementation for local hybrids was not warranted by the expected small structural improvements. ${ }^{48}$

Table 2 compares the energies and $S^{2}$ expectation values of BLYP35-D3 and Lh-SsirPW92D3 single-point calculations for all four complexes studied. Use of the local hybrid leaves the global minima generally unchanged. The most notable change at the Lh-SsirPW92-D3 level 
is the relative destabilization of the most localized/polarized conformers near $\Omega=90^{\circ}$, making them the least stable ones for both $[\mathbf{1 a}]^{+}$and $[\mathbf{1 b}]^{+}$(Table 2). We also note a smaller conformational energy spread for $[\mathbf{1} \mathbf{a}]^{+}$compared to $[\mathbf{1 b}]^{+}$and particularly compared to the two ruthenium complexes $[\mathbf{2 a}, \mathbf{b}]^{+}$.

Table 2: Comparison of relative energies $\left(\mathrm{kJ} \mathrm{mol}^{-1}\right)$ and total spin expectation values of different conformers of mixed-valence cations at global (BLYP35-D3) and local (Lh-SsirPW92-D3) hybrid DFT levels. ${ }^{\text {a }}$

\begin{tabular}{|c|c|c|c|c|c|c|c|c|c|}
\hline \multicolumn{5}{|c|}{$[\mathbf{1 a}]^{+}$} & \multicolumn{5}{|c|}{$[\mathbf{2 a}]^{+}$} \\
\hline & \multicolumn{2}{|c|}{ BLYP35-D3 } & \multicolumn{2}{|c|}{ Lh-SsirPW92-D3 } & \multicolumn{3}{|c|}{ BLYP35-D3 } & \multicolumn{2}{|c|}{ Lh-SsirPW92-D3 } \\
\hline $\begin{array}{c}\Omega \\
{\left[{ }^{\circ}\right]}\end{array}$ & $\begin{array}{c}\text { rel. E } \\
{[\mathrm{kJ} / \mathrm{mol}]}\end{array}$ & $<\mathrm{S}^{2}>$ & $\begin{array}{c}\mathrm{rel} \mathrm{E} \\
{[\mathrm{kJ} / \mathrm{mol}]}\end{array}$ & $<\mathrm{S}^{2}>$ & $\begin{array}{c}\Omega \\
{\left[{ }^{\circ}\right]}\end{array}$ & $\begin{array}{c}\text { rel. E } \\
{[\mathrm{kJ} / \mathrm{mol}]}\end{array}$ & $<\mathrm{S}^{2}>$ & $\begin{array}{c}\text { rel E } \\
{[\mathrm{kJ} / \mathrm{mol}]}\end{array}$ & $<\mathrm{S}^{2}>$ \\
\hline 55 & 0.0 & 0.83 & 0.0 & 0.79 & 36 & 2.1 & 0.77 & 2.1 & 0.76 \\
\hline 94 & 1.7 & 0.83 & 8.8 & 0.79 & 51 & 0.0 & 0.77 & 0.0 & 0.76 \\
\hline \multirow[t]{2}{*}{110} & 3.4 & 0.83 & 4.8 & 0.79 & 69 & 4.6 & 0.77 & 11.8 & 0.76 \\
\hline & & & & & 105 & 20.2 & 0.77 & 25.5 & 0.76 \\
\hline \multirow[t]{2}{*}{144} & 8.3 & 0.83 & 6.0 & 0.79 & 132 & 16.4 & 0.77 & 22.9 & 0.76 \\
\hline & & & & & 153 & 13.8 & 0.77 & 20.4 & 0.76 \\
\hline & & {$[1 \mathrm{~b}]^{+}$} & & & \multicolumn{5}{|c|}{$[\mathbf{2 b}]^{+}$} \\
\hline 36 & 0.0 & 0.82 & 0.0 & 0.79 & 33 & 0.0 & 0.77 & 0.0 & 0.76 \\
\hline 51 & 3.0 & 0.82 & 10.3 & 0.79 & 51 & 2.6 & 0.77 & 8.3 & 0.76 \\
\hline 86 & 8.5 & 0.82 & 20.6 & 0.79 & 98 & 21.0 & 0.77 & 23.0 & 0.76 \\
\hline 135 & 17.2 & 0.82 & 17.6 & 0.79 & 127 & 24.7 & 0.77 & 31.2 & 0.76 \\
\hline \multirow[t]{2}{*}{147} & 17.0 & 0.82 & 18.8 & 0.79 & 150 & 22.6 & 0.77 & 34.0 & 0.76 \\
\hline & & & & & 174 & 23.3 & 0.77 & 32.6 & 0.76 \\
\hline
\end{tabular}

${ }^{a}$ At BLYP35-D3 structures. With COSMO solvent model $\left(\mathrm{CH}_{2} \mathrm{Cl}_{2}\right)$ for both structure optimizations and single-point runs.

The spin-density distribution in the mono-cationic iron complexes (Lh-SsirPW92-D3/def2SVP level; Table S3, Figure S8) largely tracks the composition of the frontier orbitals (Table S4, Figure S9), and supports the description of $[\mathbf{1 a}]^{+}$and $[\mathbf{1 b}]^{+}$in terms of a localized electronic structure (i.e. as a Robin/Day Class II mixed-valence complex) (Figure 4). That is, for the global minima the SOMO is distributed unevenly over the two metal centers and the bridge (SOMO Fe(1)/ $\mathrm{C}_{4} / \mathrm{Fe}(2)$ : $[\mathbf{1 a}]^{+}, \Omega=55^{\circ}, 7 / 25 / 57 \%$; $[\mathbf{1 b}]^{+}, \Omega=36^{\circ}, 10 / 29 / 51 \%$ ). The HOMO is similarly polarized, but localized on the other metal center (HOMO $\left.\mathrm{Fe}(1) / \mathrm{C}_{4} / \mathrm{Fe}(2):[\mathbf{1 a}]^{+}, \Omega=55^{\circ}, 49 / 31 / 9 \% ;[\mathbf{1 b}]^{+} \Omega=36^{\circ}, 50 / 25 / 15 \%\right)$. Plots of these orbitals and total spin density (Figure 4) show that the latter reflects the SOMO composition but also some spin polarization effects (cf. negative spin density in red color). Similar molecular orbital and spin-density distributions are found for the other conformers, while it is apparent 
that the structures become even more localized for the more 'perpendicular' conformers (in particular with $\Omega \approx 90^{\circ}$; Tables S3, S4, Figures S8, S9). In contrast to the delocalized picture established for the ruthenium complexes (Tables S3, S4, Figures S8, S9), ${ }^{14}, 16$ the spin densities (and the structures) clearly point to a partially localized picture for the iron complexes $[\mathbf{1 a}]^{+}$and $[\mathbf{1 b}]^{+}$. The more localized description of the iron complexes $[\mathbf{1 a}]^{+}$and $[\mathbf{1 b}]^{+}$furthermore leads to a relatively small contribution of the $\mathrm{C}_{4}$ bridging ligand of about $25-30 \%$ to the overall spin density (adding up both positive and negative atomic spin populations), while the $\mathrm{C}_{4}$ fragment supports almost $50 \%$ of the spin density for the ruthenium systems $[\mathbf{2 a}]^{+}$and $[\mathbf{2 b}]^{+}$. It should be noted in passing that the Lh-SsirPW92-D3 local hybrid gives a somewhat less localized and less spin-polarized distribution for the iron complexes than the BLYP35-D3 global hybrid (Table S3, Figure S8), even when using the BLYP35-D3 structures. The smaller valence-shell spin polarization over the bridge is directly related to the somewhat lower $S^{2}$ expectation value.

The asymmetry and associated dipole moment computed across the long axis of polarized $[\mathbf{1} \mathbf{a}]^{+}$and $[\mathbf{1 b}]^{+}$readily explain the intensity of both the 'symmetric' and 'asymmetric' $v(\mathrm{C} \equiv \mathrm{CC} \equiv \mathrm{C})$ stretches observed in their IR spectra, indicating that the electronic structure remains localized on the IR timescale (ca. $10^{13} \mathrm{~s}^{-1}$ ). ${ }^{49-50}$ In contrast, for the more delocalized ruthenium and rhenium complexes $[\mathbf{2 a}]^{+},[\mathbf{2 b}]^{+}{ }^{16}$ and $\left[\left\{\operatorname{Re}\left(\mathrm{PPh}_{3}\right)(\mathrm{NO}) \mathrm{Cp}^{*}\right\}_{2}(\mu-\right.$ $\mathrm{C} \equiv \mathrm{CC} \equiv \mathrm{C})]^{+}{ }^{6}$, the symmetric stretch only appears as an exceptionally weak band, which only gains intensity due to the small polarization of the most perpendicular conformers. Consequently only the $v(\mathrm{C} \equiv \mathrm{CC} \equiv \mathrm{C})$ stretch corresponding to the asymmetric atom displacement is observed to have any appreciable intensity, and the IR spectra are dominated by a single, strong $v(\mathrm{C} \equiv \mathrm{CC} \equiv \mathrm{C})$ band. 


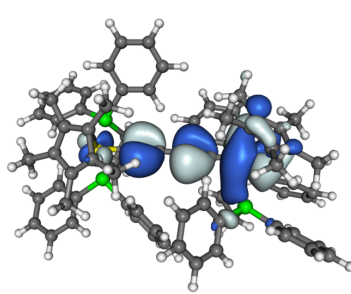

SOMO $[\mathbf{1 a}]^{+}$

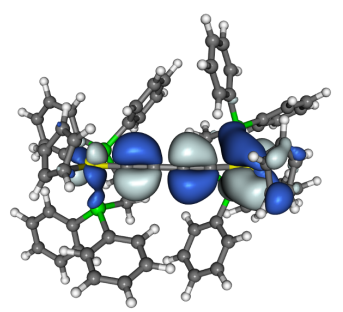

$\mathrm{SOMO}[\mathbf{1 b}]^{+}$

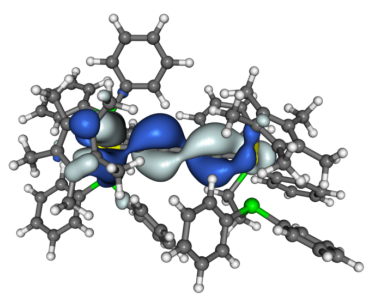

$\mathrm{HOMO}[\mathbf{1 a}]^{+}$

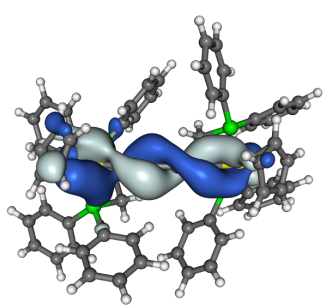

$\mathrm{HOMO}[\mathbf{1 b}]^{+}$

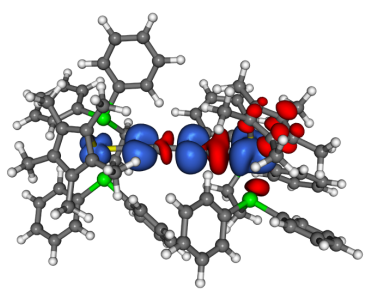

$\mathrm{SD}[\mathbf{1 a}]^{+}$

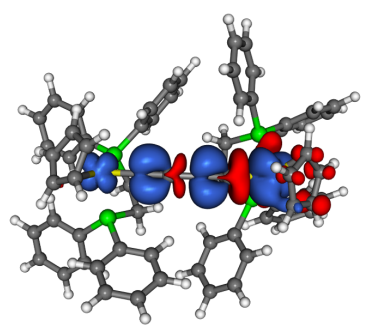

$\mathrm{SD}[\mathbf{1 b}]^{+}$

Figure 4. Frontier molecular orbital plots (isosurface: \pm 0.02 a.u.) and spin-density plots (isosurface: \pm 0.001 a.u.) for $[\mathbf{1 a}]^{+}\left(\Omega=55^{\circ}\right)$ and $[\mathbf{1 b}]^{+}\left(\Omega=36^{\circ}\right)$ using Lh-SsirPW92D3/def2-SVP (red color in the spin density marks negative values). Plots of related orbitals and spin-density distributions for other minima are given in the Supporting Information

A further characteristic feature of mixed-valence complexes is the low-energy "inter-valence charge transfer" (IVCT) band, which is often observed in the NIR to IR region. In the case of $[\mathbf{2 a}]^{+}$and $[\mathbf{2 b}]^{+}$, the NIR band envelope has been assigned on the basis of a detailed computational (TDDFT with BLYP35-D3), structural, and spectroscopic study, and was shown to arise from a series of HOMO-1 to SOMO transitions with significant $\pi-\pi^{*}$ character involving orbitals delocalized over the 6-atom Ru-C 4 -Ru chain (Table S5). ${ }^{16}$ In the conformers with the most perpendicular mutual arrangements of the half-sandwich fragments, these transitions are blue-shifted, accounting for the high-energy shoulder, and gain a degree of MLCT character (Figure 5). In addition, a weak electronic transition in the IR region is also observed. It arises from $\pi-\pi^{*}$ type transitions (HOMO-SOMO) between orbitals that are essentially orthogonal $\pi$-faces of the butadiyne bridge and delocalized over the $\mathrm{Ru}-\mathrm{C}_{4}-\mathrm{Ru}$ chains. This transition might be approximated as a dd transition if the contributions from the carbon atoms are ignored. Further single-point TDDFT calculations performed here with the local hybrid functional (Lh-SsirPW92-D3) at these previously identified structures give essentially the same description of the electronic spectra (Table S5, S6). 

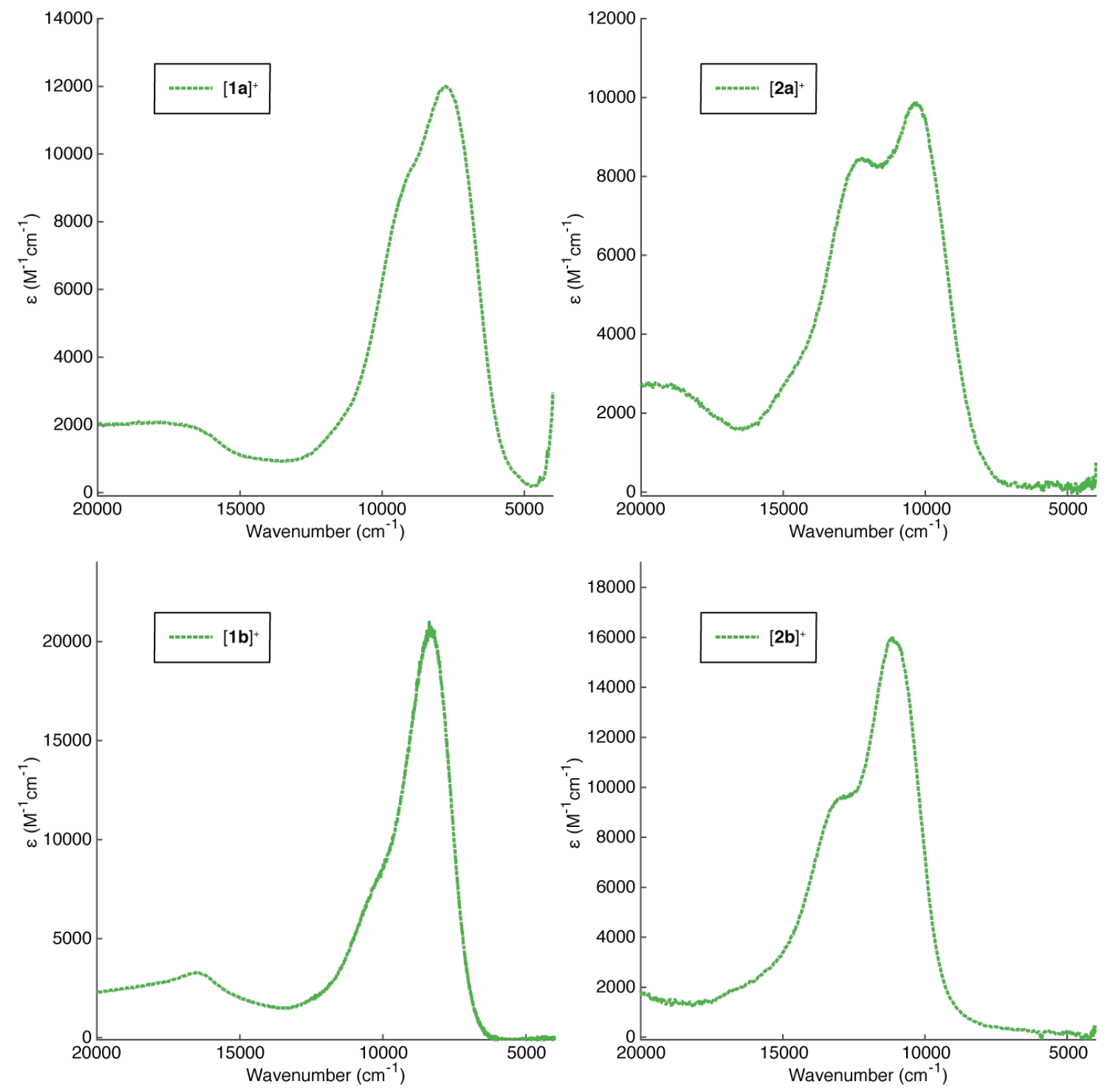

Figure 5. The spectroelectrochemically generated NIR spectra of $[\mathbf{1 a}, \mathbf{b}]^{+}$and $[\mathbf{2 a}, \mathbf{b}]^{+}$in $\mathrm{CH}_{2} \mathrm{Cl}_{2} / 0.1 \mathrm{M} \mathrm{NBu}_{4}\left[\mathrm{PF}_{6}\right]$ at room temperature.

The NIR region of both $[\mathbf{1 a}]^{+3,5}$ and $[\mathbf{1 b}]^{+}$, both of which have been recorded here using spectroelectrochemical techniques, taking care to ensure a rigorously dry and anaerobic environment within the cell (Figure 5), are dominated by a broad and relatively intense band envelope $\left(\varepsilon=12000\left([\mathbf{1 a}]^{+}\right) ; 22000\left([\mathbf{1 b}]^{+}\right) \mathrm{M}^{-1} \mathrm{~cm}^{-1}\right)$ that extends between ca. $12000-5000$ $\mathrm{cm}^{-1}$, with a higher-energy shoulder that is most pronounced for $[\mathbf{1 a}]^{+}$. This absorption band envelope has been assigned as the 'Class III' IVCT (or charge resonance) transition in previous studies of $[\mathbf{1 a}]^{+2-5}$ 
While use of the local hybrid thus does not alter the picture for the ruthenium complexes relative to BLYP35-D3 data, the BLYP35-D3 excitation spectra for $[\mathbf{1 a}]^{+}$and $[\mathbf{1 b}]^{+}$do not reproduce the experimental spectra at all well (Figure S10). Using the Lh-SsirPW92-D3 local hybrid instead leads to dramatically improved agreement with experiment (Table S6, Figure $\mathrm{S} 10)$, which is the main reason for extending our previous computational protocol to local hybrids in the case of the iron complexes. ${ }^{41-42,51}$ Results for the range of conformational minima (see above) of the iron complexes are given in Table 3. The excitations include a very low-energy electronic transition, $E_{1}$, in the IR region $\left([\mathbf{1} \mathbf{a}]^{+} E_{1}=2416-2993 \mathrm{~cm}^{-1}\right)$; $[\mathbf{1 b}]^{+} E_{1}=2925-3689 \mathrm{~cm}^{-1}$ ) and well beyond the range of the NIR spectrometer used in the original report. ${ }^{3}$ While overlapped by vibrational features, the corresponding band can be readily observed in the IR spectra of $[\mathbf{1 a}]^{+}\left(\sim 2500 \mathrm{~cm}^{-1}\right)$ and $[\mathbf{1 b}]^{+}\left(\sim 2750 \mathrm{~cm}^{-1}\right)$ (Figure 6, Figure 7). 


\begin{tabular}{|c|c|c|c|c|c|c|c|c|c|c|c|c|c|}
\hline & $\Omega_{\left({ }^{\circ}\right)}$ & $\begin{array}{c}\mathrm{E}_{1} \\
\mathrm{~cm}^{-1}\end{array}$ & $\begin{array}{l}\mu \\
D\end{array}$ & $\begin{array}{c}\mathrm{E}_{2} \\
\mathrm{~cm}^{-1}\end{array}$ & $\begin{array}{l}\mu \\
D\end{array}$ & $\begin{array}{c}\mathrm{E}_{3} \\
\mathrm{~cm}^{-1}\end{array}$ & $\begin{array}{l}\mu \\
D\end{array}$ & $\begin{array}{c}\mathrm{E}_{4} \\
\mathrm{~cm}^{-1}\end{array}$ & $\begin{array}{l}\mu \\
D\end{array}$ & $\begin{array}{c}\mathrm{E}_{5} \\
\mathrm{~cm}^{-1}\end{array}$ & $\begin{array}{l}\mu \\
D\end{array}$ & $\begin{array}{c}\mathrm{E}_{6} \\
\mathrm{~cm}^{-1}\end{array}$ & $\begin{array}{l}\mu \\
D\end{array}$ \\
\hline \multirow{5}{*}[\mathbf{1}\mathbf{a}]{$^{+}$} & 55 & 2900 & 0.5 & 6043 & 1.8 & 11234 & 5.4 & 13255 & 1.5 & 16266 & 1.2 & & \\
\hline & 94 & 2416 & 0.4 & 5656 & 0.8 & 12405 & 4.2 & 12636 & 2.9 & 15882 & 1.2 & & \\
\hline & 110 & 2667 & 0.9 & 5819 & 0.2 & 12084 & 4.7 & 13226 & 2.4 & 13744 & 0.2 & 16048 & 0.9 \\
\hline & 144 & 3168 & 1.2 & 6416 & 0.8 & 10325 & 6.3 & 10857 & 2.8 & 13546 & 0.5 & 16403 & 0.8 \\
\hline & $\operatorname{Exp}^{\dagger}$ & 2380 & & 7766 & & 9320 & & & & & & & \\
\hline \multirow{6}{*}[\mathbf{1b}]{$^{+}$} & 36 & 3689 & 1.1 & 7017 & 2.0 & 9584 & 7.0 & 13794 & 0.9 & 15613 & 0.1 & 16683 & 0.8 \\
\hline & 51 & 3384 & 1.3 & 6807 & 2.3 & 10318 & 6.0 & 11013 & 2.9 & 13434 & 1.4 & 16122 & 1.1 \\
\hline & 86 & 2925 & 0.5 & 6255 & 0.4 & 12180 & 4.6 & 12868 & 3.4 & 16327 & 0.8 & 17109 & 1.4 \\
\hline & 135 & 3298 & 1.7 & 6769 & 1.4 & 9635 & 7.0 & 13326 & 1.0 & 15492 & 0.7 & 16267 & 1.1 \\
\hline & 147 & 3689 & 1.7 & 7174 & 0.9 & 9310 & 7.7 & 13676 & 0.6 & 14367 & 0.2 & 15363 & 0.2 \\
\hline & $\operatorname{Exp}^{\dagger}$ & 2640 & & 8332 & & 10800 & & & & & & & \\
\hline \multirow{7}{*}[\mathbf{2}\mathbf{a}]{$^{+}$} & 36 & 2545 & 0.9 & 11912 & 2.5 & 12377 & 6.0 & 13702 & 5.1 & & & & \\
\hline & 51 & 1979 & 1.3 & 11778 & 0.3 & 12061 & 5.7 & 13653 & 5.8 & & & & \\
\hline & 69 & 1177 & 1.3 & 11178 & 4.2 & 11531 & 3.2 & 14193 & 5.9 & & & & \\
\hline & 105 & 805 & 1.4 & 11084 & 4.3 & 11446 & 2.6 & 14270 & 6.1 & & & & \\
\hline & 132 & 2137 & 1.2 & 11911 & 2.9 & 12134 & 4.9 & 13952 & 5.9 & & & & \\
\hline & 153 & 2724 & 0.6 & 12211 & 1.4 & 12529 & 6.5 & 13525 & 5.0 & & & & \\
\hline & $\operatorname{Exp}^{\dagger}$ & 2230 & & 10340 & & 12420 & & & & & & & \\
\hline \multirow{7}{*}[\mathbf{2b}]{$^{+}$} & 33 & 2765 & 1.1 & 13073 & 7.9 & 13771 & 0.6 & 14761 & 1.5 & & & & \\
\hline & 51 & 2519 & 1.3 & 12958 & 7.1 & 13842 & 1.5 & 14865 & 3.0 & & & & \\
\hline & 98 & 836 & 1.6 & 12693 & 5.2 & 13101 & 2.7 & 14570 & 5.2 & & & & \\
\hline & 127 & 2256 & 1.3 & 13139 & 7.0 & 13948 & 1.7 & 14877 & 3.2 & & & & \\
\hline & 150 & 2779 & 0.9 & 13500 & 8.0 & 14182 & 0.5 & 14961 & 1.1 & & & & \\
\hline & 174 & 3375 & 0.2 & 13376 & 8.4 & 14599 & 1.1 & & & & & & \\
\hline & $\operatorname{Exp}^{\dagger}$ & 2590 & & 11140 & & 13190 & & & & & & & \\
\hline
\end{tabular}

${ }^{\dagger}$ Apparent peak maxima (literature data for $[\mathbf{2 a}]^{+}$and [2b] quoted).16. Gluyas, J. B. G.; Guckel, S.; Kaupp, M.; Low, P. J., Rational Control of Conformational Distributions and Mixed-Valence Characteristics in Diruthenium Complexes. Chem-Eur J 2016, 22 (45), 16138-16146. 


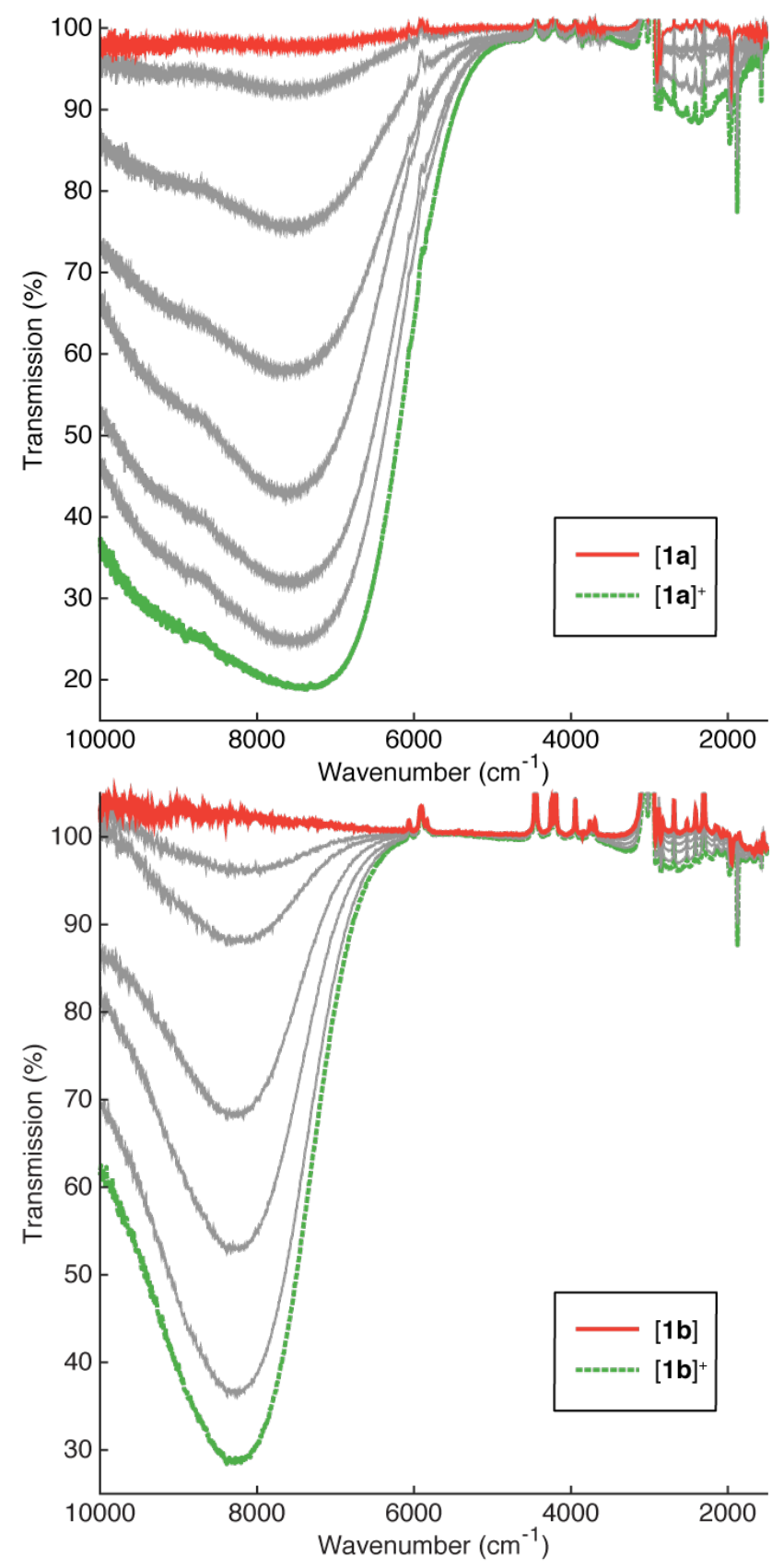

Figure 6. The reversible spectral changes observed upon spectroelectrochemical oxidation of $[\mathbf{1 a}, \mathbf{b}] \rightarrow[\mathbf{1 a}, \mathbf{b}]+$ in the $1000-10000 \mathrm{~cm}^{-1}$ region. 

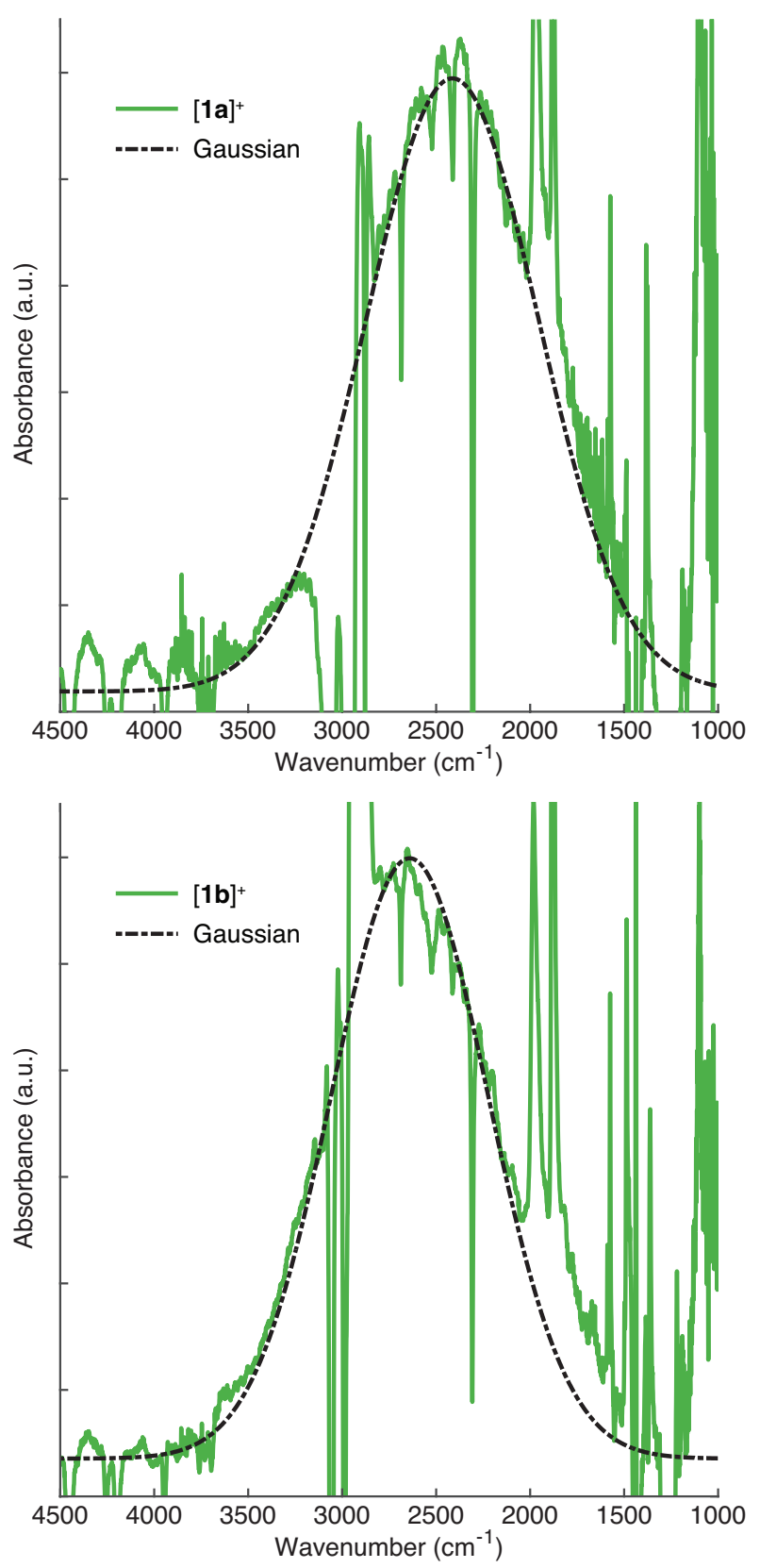

Figure 7. The low-intensity Gaussian-shaped bands observed in the $\sim 2500 \mathrm{~cm}^{-1}$ region of the spectra of $[\mathbf{1} \mathbf{a}]^{+}$(upper) and $[\mathbf{1 b}]^{+}$(lower).

The TDDFT calculations attribute $E_{1}$ to the HOMO-SOMO excitation, admixed with HOMO-1 to SOMO and HOMO-3 to SOMO character (the precise composition varies for each conformer; Tables 3, S6). The HOMO-1 to SOMO excitation is a more important contribution for the more cis- and trans-like conformers, whilst HOMO-3 to SOMO is more significant in the more perpendicular conformers. The $E_{1}$ transition red-shifts and decreases in intensity in the more perpendicular conformers. Given the differences in the localization of the HOMO, HOMO-1 and HOMO-3, all 
of which feature significant $\mathrm{Fe}(1)$ character, and the SOMO, which has appreciable $\mathrm{Fe}(2)$ character, these low-energy IR bands for $[\mathbf{1} \mathbf{a}, \mathbf{b}]^{+}$are well described as part of the IVCT transitions associated with Class II (valence-localized) mixed-valence complexes based on pseudo-octahedral $\mathrm{d}^{5}-\mathrm{d}^{6}$ metal fragments. ${ }^{52}$ Such descriptions should not, however, overlook the important contributions of the $\mathrm{C}_{4}$ chain to the frontier orbitals. The SOMO has ca. $25 \%$ or $30 \% \mathrm{C}_{4}$ character in all conformers of $[\mathbf{1 a}]^{+}$and $[\mathbf{1 b}]^{+}$, respectively (even when averaging the negative and positive regions created by spin polarization, see above). The HOMO-1 and HOMO-3 feature opposite trends in their carbon character, with the carbon character decreasing in the more perpendicular conformers in HOMO-1, and rising in the case of the HOMO-3. In terms of the traditional two-state model of mixed-valence complexes, $E_{1}$ might well be described as the true IVCT transition.

The TDDFT calculations (Lh-SsirPW92-D3//BLYP35-D3) provide a second transition of relatively low oscillator strength $\left(E_{2}\right)$ that is also red-shifted and decreases in intensity for the perpendicular conformers, falling between $5656-6416$ $\mathrm{cm}^{-1}\left([\mathbf{1} \mathbf{a}]^{+}\right)$and between $6255-7174 \mathrm{~cm}^{-1}\left([\mathbf{1 b}]^{+}\right)$. This $E_{2}$ transition arises from HOMO-4 and HOMO-5 to SOMO excitations, admixed with smaller contributions from the HOMO to SOMO excitation (the HOMO-5 contribution becomes more dominant for the more perpendicular isomers). On the basis of the composition of the HOMO-4 $\left(\Omega=110^{\circ},[\mathbf{1 a}]^{+}, \mathrm{Fe}(1) / \mathrm{C}_{4} / \mathrm{Fe}(2): 40 / 11 / 8 ; \Omega=86^{\circ},[\mathbf{1 b}]^{+}: 33 / 19 / 24\right)$ and HOMO-5 $\left(\Omega=110^{\circ},[\mathbf{1 a}]^{+}, \mathrm{Fe}(1) / \mathrm{C}_{4} / \mathrm{Fe}(2): 7 / 11 / 47 ; \Omega=86^{\circ},[\mathbf{1 b}]^{+}: 13 / 10 / 52\right)$, the low-intensity $E_{2}$ transition can be described as arising from an MLCT excitation, although the relatively low oscillator strength makes the definitive assignment of features of this transition in the experimental spectrum uncertain.

The $E_{3}$ transitions provided by the TDDFT calculations have much greater oscillator strength than $E_{1}$ and $E_{2}$ and fall between $10325-12405 \mathrm{~cm}^{-1}\left([\mathbf{1 a}]^{+}\right)$and between $9310-12180 \mathrm{~cm}^{-1}\left([\mathbf{1 b}]^{+}\right)$across the range of conformations identified. As with the other electronic transitions, the composition of $E_{3}$ is modestly sensitive to the conformation, decreasing in intensity but blue-shifting in the case of the more perpendicular conformers. These $E_{3}$ transitions from the most perpendicular conformers are in part responsible for the shoulder observed in the experimental spectra (Figure 5). The $E_{3}$ transitions of $[\mathbf{1 b}]^{+}$cover a narrower range than those of 
$[\mathbf{1 a}]^{+}$, neatly accounting for the narrower NIR absorption envelope observed in the Cp derivative and the more significant shoulder seen with the $\mathrm{Cp}^{*}$ derivative. The $E_{3}$ transitions involve HOMO to SOMO and HOMO-1 to SOMO excitations and much smaller contributions from the HOMO-2 to SOMO excitation. The HOMO to SOMO component is most significant for the most cis- and trans-like conformers, while the HOMO-1 to SOMO contribution dominates for perpendicular conformers and is more prevalent in the transitions that give rise to the higher-energy shoulder. The HOMO-1 has a similar polarization as the HOMO, and therefore $E_{3}$ also exhibits significant IVCT character. The NIR envelope also contains transition $E_{4}$, which also has dominant HOMO-1 to SOMO character and occurs at $10857-13255 \mathrm{~cm}^{-1}\left([\mathbf{1 a}]^{+}\right)$and at $11013-13794 \mathrm{~cm}^{-1}\left([\mathbf{1 b}]^{+}\right)$, depending on conformation. It is also worth noting that the potential energy surface of $[\mathbf{1 a}]^{+}$appears to be very shallow region in the region around $\Omega=144^{\circ}$. When adding a sampling point in that region $\left(\Omega=144^{\circ}\right)$, the additional transitions result in the computed shoulder on the band around 10,000 $12,000 \mathrm{~cm}-1$ becoming more prominent, leading to better agreement with the experimental spectrum (Figure S11). Whilst it is therefore likely that not every minimum has been identified, the consolidated body of results strongly support the use of the conformational distribution sampling a number of close lying minima rather than a single point calculation to achieve greater accuracy in the description of the electronic absorption spectra. Whilst the solvatochromic character of this band envelope is not dramatic, varying over only ca. $160 \mathrm{~cm}^{-1}$ from $\mathrm{CH}_{2} \mathrm{Cl}_{2}$ to $\mathrm{NCMe}^{3}$ this may be due to the effective screening of the $\mathrm{Fe}_{2} \mathrm{C}_{4}$ chain from the solvent by the ancillary ligand sphere, and is still significantly greater than that of $[\mathbf{2 a}]^{+}{ }^{14}$

Finally, the highest-energy optical absorption bands observed in the experimental spectra of $[\mathbf{1 a}]^{+}$and $[\mathbf{1 b}]^{+}$at $15000-17000 \mathrm{~cm}^{-1}$ arise from $E_{5}$ and $E_{6}$ which have dominantly HOMO-2 to SOMO character in each case across the range of conformers. The HOMO-2 is largely associated with $\mathrm{Fe}(1)$, and therefore this highestenergy band also has a degree of metal-to-metal charge transfer character. Multiple transitions with IVCT character are not uncommon for localized $\mathrm{d}^{5} / \mathrm{d}^{6}$ dinuclear mixed-valence complexes, ${ }^{52}$ and Figure 8 shows the good match of the computed spectra (obtained when convoluting the stick spectra of the various conformers at LhSsirPW92-D3//BLYP35-D3 level with Gaussian functions of half-width $800 \mathrm{~cm}^{-1}$ ) with the spectroelectrochemically determined experimental spectra. 

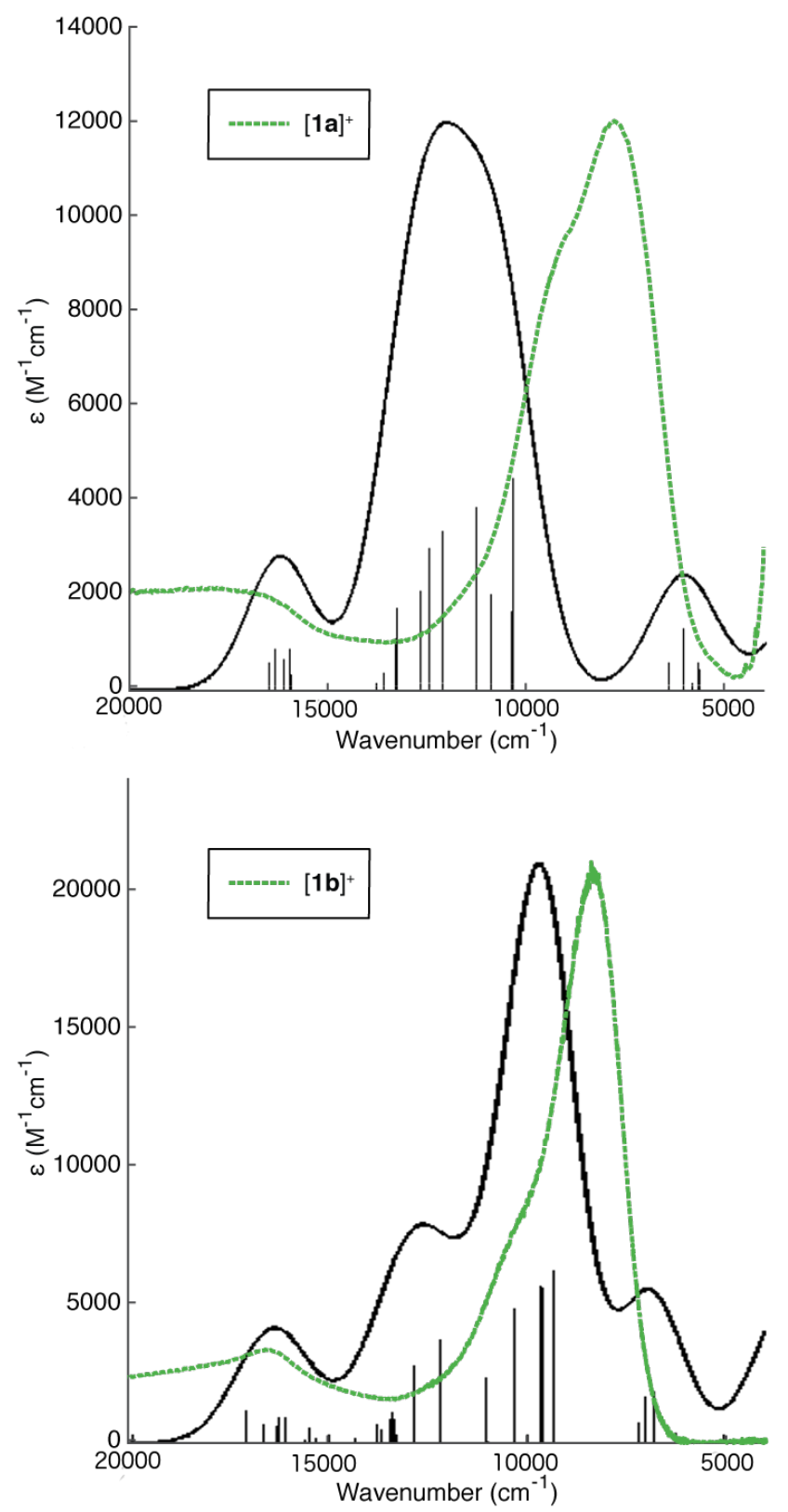

Figure 8 . The spectroelectrochemically generated NIR spectra of $[\mathbf{1 a}, \mathbf{b}]^{+}$(green, dotted lines) and computed spectra, convoluting a simple average of the stick spectra of the various conformers (black, solid line, with stick spectra).

Finally, it is interesting to consider the underlying reasons for the distinct electronic characters of the more localized iron complexes $[\mathbf{1 a}]^{+},[\mathbf{1 b}]^{+}$, and the more extensively delocalized ruthenium complexes $[\mathbf{2 a}]^{+},[\mathbf{2 b}]^{+}$. The degree of electronic interaction between the two half-sandwich redox centers, and hence the degree of (de)localization is a result of the overlap of the valence orbitals of the metal centers Fe: $3 \mathrm{~d}, \mathrm{Ru}: 4 \mathrm{~d})$ and the bridging ligand $\left(\mathrm{C}_{4}: \pi\right.$-system). Due to their larger spatial extension, the $4 \mathrm{~d}$-orbitals of ruthenium overlap better with the $\pi$-system of the 
butadiyndiyl-bridge than do the 3d-orbitals of iron which are exceptionally compact due to the lack of a radial node. ${ }^{53}$ These differences in atomic orbital structure contribute to more delocalization of charge in case of the largely Class III ruthenium systems while the iron complexes exhibit an appreciably more localized Class II behavior. In addition, the role that ancillary ligands may play through steric and dispersion effects on the conformational distribution and hence underlying electronic properties is also worthy of further investigation; complex $[\mathbf{1 c}]^{+}$represents a useful target through which to explore these ancillary ligand effects, which will be the subject of later studies.

\section{Conclusions}

The present organometallic $\mathrm{C}_{4}$-bridged mixed-valence iron and ruthenium complexes $[\mathbf{1} \mathbf{a}, \mathbf{b}]^{+}$and $[\mathbf{2} \mathbf{a}, \mathbf{b}]^{+}$, respectively, have been prototype systems for the study of mixedvalency, electron transfer, and in general for all-carbon bridging ligands for several decades. The present finding that the diiron complexes $[\mathbf{1} \mathbf{a}, \mathbf{b}]^{+}$are on the localized Class II side of the mixed-valence spectrum, at least on the time scale of the IR experiment $\left(10^{-13} \mathrm{~s}\right)$, puts them into marked contrast to the delocalized Class III ruthenium complexes $[\mathbf{2} \mathbf{a}, \mathbf{b}]^{+}$, while thus far much more similarity between the two types had been assumed. This interesting electronic-structure counterpoint highlights the differences in metal-ligand overlap for $3 \mathrm{~d}$ and $4 \mathrm{~d}$ systems, and indicates that in the case of 'all carbon' or 'carbon-rich' bridged bimetallic complexes, first row metals are more likely to result in 'localized' (Class II) behavior whilst second and third row metal likely give more delocalized structures. Of course, the question of 'localized' or 'delocalized' character is intricately related to the time-scale of observation and on the longer timescale of ESR and Mossbauer spectroscopies, [1a $]^{+}$appears to be more fully delocalized, the effective electron transfer rate between the two iron centers can be estimated between $10^{-9}-10^{-13} \mathrm{~s}$.

The localized character of the two diiron systems manifests itself in the observation of symmetric and asymmetric $v(\mathrm{C} \equiv \mathrm{CC} \equiv \mathrm{C})$ stretches with significant IR intensity. This contrasts with barely detectable symmetric stretches for the delocalized ruthenium and closely related rhenium examples, where the symmetric stretch only gains some intensity due to the larger symmetry breaking in the most perpendicular conformers. 
A comprehensive DFT investigation has identified a range of structural minima, which differ in the relative orientation of the half-sandwich fragments across the $\mathrm{C}_{4}$ ligand, but which feature structural features consistent with oxidation at only one iron center and which is localized on the IR timescale. Harmonic vibrational frequency analyses for these conformers account for the appearance of the experimental IR spectra. Moreover, the calculations indeed show $[\mathbf{1} \mathbf{a}, \mathbf{b}]^{+}$to be localized Class II and $[\mathbf{2 a}, \mathbf{b}]^{+}$to be delocalized Class III.

Electronic excitation spectra in the NIR (and IR) region also reflect the rich conformational landscape, and the computations help explain some intriguing features of the spectra, such as the identification of a new, low-energy IVCT band in the IR region (for both the iron and ruthenium systems). Further electronic absorptions in the NIR region arise from overlapping IVCT-like transitions in each of the thermally accessible conformers. For the study of these electronic excitations, we had to extend our BLYP35-D3-based computational protocol for the treatment of mixed-valence systems: while the spectra for the diruthenium complexes are well reproduced with BLYP35-D3, this is not the case for the mixed-valence diiron systems, likely due to the onset of significant spin contamination. Here the use of a novel type of exchangecorrelation functionals, so-called local hybrids with position-dependent exactexchange admixture, provided the necessary improvements: whilst keeping electronic structure and spectra essentially unchanged compared to BLYP35-D3 for the ruthenium complexes, the electronic spectra of the iron complexes were decisively improved, allowing their detailed interpretation.

The presence of multiple conformers in all but the most symmetric of 'mixedvalence' systems, all of which offer subtly different electronic transitions, makes application of band-shape analysis within the framework of Marcus-Hush theory fraught with difficulty. The apparent band envelope maxima and molar extinction coefficients of the absorption spectra arise from these overlapping transitions from different conformers, and cannot necessarily be attributed to any single conformer. Uncertainties in the precise composition of the equilibrated conformational mixture mean that accurate deconvolution and attribution of components of the band envelope to any individual conformer or electronic transition is not possible. Detailed computational analyses of spin-density distributions and of the composition of the 
frontier molecular orbitals nevertheless allow the electronic coupling between the redox centers and the overall electronic structure, and the spectroscopy of such systems, to be understood, provided appropriate computational approaches are applied.

Experimental Details. The compounds $\mathrm{FeI}(\mathrm{CO})_{2} \mathrm{Cp},{ }^{54} \mathrm{FeCl}(\mathrm{dppe}) \mathrm{Cp}^{55}$ and $[\mathbf{1 a}]^{\mathrm{n}+3}$ were synthesized according to existing literature procedures. The preparation, purification and reactions of the complexes described were carried out under dry nitrogen. All solvents were dried by standard methods, distilled and deoxygenated before use. NMR spectra were recorded on a Bruker Avance III HD $\left(500 \mathrm{MHz}{ }^{1} \mathrm{H}\right.$, $\left.125 \mathrm{MHz}{ }^{13} \mathrm{C}\left\{{ }^{1} \mathrm{H}\right\}, 202 \mathrm{MHz}{ }^{31} \mathrm{P}\left\{{ }^{1} \mathrm{H}\right\}\right)$ spectrometer and referenced to internal solvent references $\left({ }^{1} \mathrm{H},{ }^{13} \mathrm{C}\left\{{ }^{1} \mathrm{H}\right\}\right)$ or external $85 \% \mathrm{H}_{3} \mathrm{PO}_{4}\left({ }^{31} \mathrm{P}\left\{{ }^{1} \mathrm{H}\right\} \delta=0.0\right)$. Infrared spectra (solid state) were obtained on a Nicolet iS5 FT-IR or an Agilent Technologies Cary 630 spectrometer fitted with an ATR attachment. Electrospray mass spectra were obtained on a Waters SQD2 instrument and MALDI mass spectra were recorded using a Shimadzu Axima Confidence spectrometer. Microanalyses were conducted by the staff of the Microanalytical Service of the School of Chemistry, University of Manchester. Cyclic voltammetry was carried out as previously reported using the decamethylferrocene/decamethylferrocinium $\left(\mathrm{FeCp}_{2}^{*} /\left[\mathrm{FeCp}_{2}\right]^{+}\right)$couple as an internal reference for potential measurements (as the usual ferrocene reference couple overlapped with a wave in the $\mathrm{CV}$ of $\mathbf{1 b}$ ) such that the couple falls at $-0.55 \mathrm{~V}$ $\left(\mathrm{CH}_{2} \mathrm{Cl}_{2} / \mathrm{NBu}_{4} \mathrm{PF}_{6}\right)$ relative to external $\mathrm{FeCp}_{2} /\left[\mathrm{FeCp}_{2}\right]^{+}$at $0.00 \mathrm{~V}^{57}$ Spectroelectrochemical measurements were conducted as previously described. ${ }^{16}$

\section{$\mathrm{Fe}(\mathrm{C} \equiv \mathrm{CH})(\mathrm{dppe}) \mathrm{Cp}$}

Ethynyltrimethylsilane $(443 \mathrm{mg}, 4.51 \mathrm{mmol})$ was added to a solution of $\mathrm{FeCl}(\mathrm{dppe}) \mathrm{Cp}(500 \mathrm{mg}, 903 \mu \mathrm{mol})$ and ammonium hexafluorophosphate (294 mg, $1.81 \mathrm{mmol})$ in methanol $(10 \mathrm{~mL})$, the reaction mixture was heated at reflux for $1 \mathrm{~h}$ and then allowed to cool to ambient temperature. Subsequently sodium (104 mg, $4.51 \mathrm{mmol}$ ) was added to the stirred orange suspension resulting in a mildly exothermic reaction. This mixture was allowed to stir for a further $1 \mathrm{~h}$ at ambient 
temperature and filtered to afford $\mathrm{Fe}(\mathrm{C} \equiv \mathrm{CH})(\mathrm{dppe}) \mathrm{Cp}$ in $73 \%$ yield (358 $\mathrm{mg}$, $660 \mu \mathrm{mol})$ as an red/orange powder which was washed with methanol $(20 \mathrm{~mL})$ and dried in air. All analytical data were in agreement with those reported in the literature. ${ }^{58}{ }^{1} \mathrm{H}-\mathrm{NMR}\left(500.1 \mathrm{MHz}_{\mathrm{CDCl}}\right): \delta=1.31(\mathrm{~s}, 1 \mathrm{H}, \mathrm{C} \equiv \mathrm{CH}), 2.26(\mathrm{~m}, 2 \mathrm{H}$, dppe), 2.72 (m, $2 \mathrm{H}$, dppe), 4.21 (s, $5 \mathrm{H}, \mathrm{C}_{5} H_{5}$ ), 7.15 (m, $4 \mathrm{H}, o-\mathrm{C}_{6} H_{5}, \mathrm{Fe}(\mathrm{dppe}) \mathrm{Cp}$ ), 7.24 (m, $4 \mathrm{H}, m-\mathrm{C}_{6} H_{5}, \mathrm{Fe}(\mathrm{dppe}) \mathrm{Cp}$ ), 7.30 (m, $4 \mathrm{H}, m-\mathrm{C}_{6} H_{5}, \mathrm{Fe}(\mathrm{dppe}) \mathrm{Cp}$ ), 7.38 (m, $\left.4 \mathrm{H}, p-\mathrm{C}_{6} H_{5}, \mathrm{Fe}(\mathrm{dppe}) \mathrm{Cp}\right), 7.90$ (m, $\left.4 \mathrm{H}, o-\mathrm{C}_{6} H_{5}, \mathrm{Fe}(\mathrm{dppe}) \mathrm{Cp}\right) .{ }^{31} \mathrm{P}-\mathrm{NMR}(202.4$ $\left.\mathrm{MHz}, \mathrm{CDCl}_{3}\right): \delta=106.3$ (s). FT-IR $\left(\mathrm{CH}_{2} \mathrm{Cl}_{2}\right) v 1917(\mathrm{C} \equiv \mathrm{C}), 3271 \mathrm{~cm}^{-1}(\equiv \mathrm{C}-\mathrm{H})$.

$\left[\{\mathbf{F e}(\mathbf{d p p e}) \mathbf{C p}\}_{2}(\boldsymbol{\mu}-\mathbf{C}=\mathbf{C H}-\mathbf{C H}=\mathbf{C})\right]\left[\mathbf{P F}_{\mathbf{6}}\right]_{2}$ Ferrocenium hexafluorophosphate $(1.02 \mathrm{~g}$, $3.09 \mathrm{mmol})$ was added to a solution of $[\mathrm{Fe}(\mathrm{C} \equiv \mathrm{CH})(\mathrm{dppe}) \mathrm{Cp}](1.68 \mathrm{~g}, 3.09 \mathrm{mmol})$ in dichloromethane $(12 \mathrm{~mL})$ at $-78^{\circ} \mathrm{C}$ and the reaction mixture was stirred at this temperature for $3 \mathrm{~h}$. After warming to $-20^{\circ} \mathrm{C}$, diethyl ether was added to be just sufficient to induce precipitation of the required product as a green-brown solid; the remaining orange-brown solution contains the more soluble reaction by-product $\left[\mathrm{Fe}\left(\mathrm{C}=\mathrm{CH}_{2}\right)(\mathrm{dppe}) \mathrm{Cp}\right]\left[\mathrm{PF}_{6}\right]^{59}$ Recrystallization of the crude product from $\mathrm{CH}_{2} \mathrm{Cl}_{2}$ /diethyl ether afforded the product in $83 \%$ yield as a green-brown solid (2• $\mathrm{CH}_{2} \mathrm{Cl}_{2}$ solvate, $\left.1.98 \mathrm{~g}, 1.28 \mathrm{mmol}\right) .{ }^{1} \mathrm{H} \mathrm{NMR}\left(\mathrm{CD}_{2} \mathrm{Cl}_{2}\right): \delta 2.56$ (br, $4 \mathrm{H}, \mathrm{CH}_{2}$, dppe), 2.78 (br, 4H, $\mathrm{CH}_{2}$, dppe), 4.10 (br, 2H, C=CH), 4.86 (s, 10H, Cp), 6.91, 7.17, 7.28, 7.38, (m, 40H, Ph, dppe). ${ }^{13} \mathrm{C}\left\{{ }^{1} \mathrm{H}\right\} \mathrm{NMR}\left(\mathrm{CD}_{2} \mathrm{Cl}_{2}\right): 358.1$ (t, $\left.J_{\mathrm{C}-\mathrm{P}} 35 \mathrm{~Hz}\right), \mathrm{C}_{\alpha}$; 135.9, m, 134.3, m, $\mathrm{Ph}_{\mathrm{i}} ; 132.5, \mathrm{~m}, 131.1, \mathrm{~m}, \mathrm{Ph}_{\mathrm{o}} ; 131.4, \mathrm{~s}, 131.2, \mathrm{~s}, \mathrm{Ph}_{\mathrm{p}} ; 129.2, \mathrm{~m}$, 129.1, m, $\mathrm{Ph}_{\mathrm{m}}$; 109.6, s, (C=CH); 89.2, s, Cp; 28.5, m, $\mathrm{CH}_{2}$ (dppe). ${ }^{31} \mathrm{P}\left\{{ }^{1} \mathrm{H}\right\} \mathrm{NMR}$ $\left(\mathrm{CD}_{2} \mathrm{Cl}_{2}\right): \delta$ 95.7. FT-IR (ATR) $v 1636(\mathrm{w}), 1603(\mathrm{~m}) \mathrm{cm}^{-1}(\mathrm{C}=\mathrm{C})$. MALDI- MS (m/z): $1086[\mathrm{M}-2 \mathrm{H}]^{+}$. for $\mathrm{C}_{66} \mathrm{H}_{60} \mathrm{Fe}_{2} \mathrm{P}_{6} \mathrm{~F}_{12} .2 \mathrm{CH}_{2} \mathrm{Cl}_{2}$ : C, 52.7, H, 4.1; Found, C, 53.4; H, 4.0.

$[\{\mathbf{C p}($ dppe $) \mathbf{F e}\}(\boldsymbol{\mu}-\mathrm{C} \equiv \mathbf{C C} \equiv \mathbf{C})\{\mathbf{F e}($ dppe $) \mathbf{C p}\}][\mathbf{1 b}]$ A mixture of $\left[\{\mathrm{Fe}(\mathrm{dppe}) \mathrm{Cp}\}_{2}(\mu-\right.$ $\mathrm{C}=\mathrm{CH}-\mathrm{CH}=\mathrm{C})]\left[\mathrm{PF}_{6}\right]_{2}(0.77 \mathrm{~g}, 0.56 \mathrm{mmol})$ and potassium tert-butoxide $(0.13 \mathrm{~g}, 1.19$ mmol) in tetrahydrofuran $(20 \mathrm{~mL})$ was stirred at $0{ }^{\circ} \mathrm{C}$ for $15 \mathrm{~min}$ to give an orangebrown solution which was then evaporated to dryness. The reaction residue was extracted with toluene and the extract was filtered through celite, evaporated to dryness and the residue was recrystallized from $\mathrm{CH}_{2} \mathrm{Cl}_{2} / n$-hexane to afford the product as an orange-brown solid in $16 \%$ yield $(0.10 \mathrm{~g} 0.09 \mathrm{mmol}) .{ }^{1} \mathrm{H}$ NMR $\left(\mathrm{CD}_{2} \mathrm{Cl}_{2} / \mathrm{CoCp}_{2}\right): \delta 1.89$ (br, 4H, $\mathrm{CH}_{2}$, dppe), 2.16 (br, 4H, $\left.\mathrm{CH}_{2}, \mathrm{dppe}\right), 3.99$ (s, 10H, 
Cp), 7.00, 7.11, 7.24, 7.63, (m, 40H, Ph, dppe). ${ }^{13} \mathrm{C}\left\{{ }^{1} \mathrm{H}\right\}$ NMR $\left(\mathrm{CD}_{2} \mathrm{Cl}_{2} / \mathrm{CoCp}_{2}\right)$ : 142.9, m, 139.2, m, $\mathrm{Ph}_{\mathrm{i}} ; 133.7, \mathrm{~m}, 131.9, \mathrm{~m}, \mathrm{Ph}_{\mathrm{o}} ; 128.9, \mathrm{~s}, 128.5, \mathrm{~s}, \mathrm{Ph}_{\mathrm{p}} ; 127.8, \mathrm{~m}$, 127.4, m, $\mathrm{Ph}_{\mathrm{m}} ; 110.2$, s, $\mathrm{C}_{\beta} ; 88.9$ (t, $J_{\mathrm{C}-\mathrm{P}} 44 \mathrm{~Hz}$ ), C $\mathrm{C}_{\alpha} ; 78.8, \mathrm{~s}, \mathrm{Cp} ; 28.0, \mathrm{~m}, \mathrm{CH}_{2}$ (dppe). ${ }^{31} \mathrm{P}\left\{{ }^{1} \mathrm{H}\right\}$ NMR $\left(\mathrm{CD}_{2} \mathrm{Cl}_{2} / \mathrm{CoCp}_{2}\right): \delta 105.0$. FT-IR $\left(\mathrm{CH}_{2} \mathrm{Cl}_{2}\right) v 1955$ (ATR) $v 1925 \mathrm{~cm}^{-1}$ $(\mathrm{C} \equiv \mathrm{C}) . \mathrm{ES}(+) \mathrm{MS}(\mathrm{m} / \mathrm{z}): 1086[\mathrm{M}]^{+}$. Anal.: Calcd. (\%) for $\mathrm{C}_{66} \mathrm{H}_{58} \mathrm{Fe}_{2} \mathrm{P}_{4}: \mathrm{C}, 72.9, \mathrm{H}$, 4.3; Found, C, 72.8, H, 5.6. A single crystal of [1b] suitable for X-Ray diffraction studies was obtained by slow diffusion of $n$-pentane into a dichloromethane solution of [1b] at ambient temperature (c. $22{ }^{\circ} \mathrm{C}$ ) giving the $\operatorname{bis}\left(\mathrm{CH}_{2} \mathrm{Cl}_{2}\right)$ solvate. $\mathrm{C}_{68} \mathrm{H}_{62} \mathrm{Cl}_{4} \mathrm{Fe}_{2} \mathrm{P}_{4}, M=1256.56$, dark-cherry prism, $0.36 \times 0.26 \times 0.20 \mathrm{~mm}^{3}$, orthorhombic, space group Pbca (No. 61), $a=18.1113(1), b=20.7731(2), c=$ 31.5098(3) $\AA, V=11854.86(17) \AA^{3}, Z=8, D_{\mathrm{c}}=1.408 \mathrm{~g} / \mathrm{cm}^{3}, \mu=0.820 \mathrm{~mm}^{-1} . F_{000}=$ 5200, MoK $\alpha$ radiation, $\lambda=0.71073 \AA, \quad T=100(2) \mathrm{K}, 2 \theta_{\max }=75.1^{\circ}, 388734$ reflections collected, 30686 unique $\left(\mathrm{R}_{\mathrm{int}}=0.0919\right)$. Final GooF $=1.000, R_{1}=0.0560$, $w R_{2}=0.1278, R$ indices based on 21585 reflections with $I>2 \sigma(I)$ (refinement on $F^{2}$ ), $|\Delta \rho|_{\max }=2.1(1)$ e $\AA^{-3}, 703$ parameters, 0 restraints. Lp and absorption corrections applied.

\section{$[\{\mathrm{Cp}(\mathrm{dppe}) \mathrm{Fe}\}(\mu-\mathrm{C} \equiv \mathrm{CC} \equiv \mathrm{C})\{\mathrm{Fe}(\mathrm{dppe}) \mathrm{Cp}\}]\left[\mathrm{PF}_{6}\right]_{2} \quad\left([\mathbf{1 b}]\left[\mathrm{PF}_{\mathbf{6}}\right]_{2}\right) \quad$ Ferrocenium} hexafluorophosphate $(0.28 \mathrm{~g}, 0.85 \mathrm{mmol})$ was added to a solution of $\mathbf{1 b}(0.50 \mathrm{~g}, 0.46$ mmol) in dichloromethane $(20 \mathrm{~mL})$ at $0{ }^{\circ} \mathrm{C}$ and the reaction mixture was stirred at this temperature for $1 \mathrm{~h}$ resulting in a color change from orange to blue-green. The reaction mixture was filtered through Celite and treated with diethyl ether to precipitate the product in $70 \%$ yield as a deep green solid $\left(2 \cdot \mathrm{CH}_{2} \mathrm{Cl}_{2}\right.$ solvate; $0.50 \mathrm{~g}$, $0.32 \mathrm{mmol})$. FT-IR (ATR) $v 1808 \mathrm{~cm}^{-1}(\mathrm{C} \equiv \mathrm{C})$. MALDI-MS $(\mathrm{m} / \mathrm{z})[\mathrm{M}]^{+}$1086. Anal.: Calcd. (\%) for $\mathrm{C}_{66} \mathrm{H}_{58} \mathrm{Fe}_{2} \mathrm{P}_{6} \mathrm{~F}_{12} .2 \mathrm{CH}_{2} \mathrm{Cl}_{2}$ : C, 52.8, H, 4.0; Found, C, 53.4, H, 3.9.

\section{$[\{\mathrm{Cp}(\mathrm{dppe}) \mathrm{Fe}\}(\boldsymbol{\mu}-\mathrm{C} \equiv \mathrm{CC} \equiv \mathrm{C})\{\mathbf{F e}(\mathbf{d p p e}) \mathrm{Cp}\}]\left[\mathrm{PF}_{6}\right]\left(\left[\mathbf{1 b} \mathbf{P F}_{6}\right)\right.$ A sample of $[\mathbf{1 b}]\left[\mathrm{PF}_{6}\right]_{2}$}

$(0.50 \mathrm{~g}, 0.36 \mathrm{mmol})$ was dissolved in dichloromethane $(25 \mathrm{~mL})$ at $0{ }^{\circ} \mathrm{C}, \mathbf{1 b}(0.39 \mathrm{~g}$, $0.36 \mathrm{mmol}$ ) was then added and the reaction mixture was stirred at $0{ }^{\circ} \mathrm{C}$ for $1 \mathrm{~h}$. A black-green solution formed which was filtered through celite. Diethyl ether added to the filtrate resulting in formation of a precipitate which was isolated by filtration, washed with diethyl ether and dried in vacuo affording the product in 53\% yield as a black-green precipitate $\left(\mathrm{CH}_{2} \mathrm{Cl}_{2}\right.$ solvate; $\left.0.50 \mathrm{~g}, 0.38 \mathrm{mmol}\right)$. FT-IR $\left(\mathrm{CH}_{2} \mathrm{Cl}_{2}\right) v 1877$, 
$1980 \mathrm{~cm}^{-1} \quad(\mathrm{C} \equiv \mathrm{C})$. MALDI-MS (m/z) $\quad[\mathrm{M}]^{+}$1086. Anal.: Calcd. (\%) for $\mathrm{C}_{66} \mathrm{H}_{58} \mathrm{Fe}_{2} \mathrm{P}_{5} \mathrm{~F}_{6} . \mathrm{CH}_{2} \mathrm{Cl}_{2}$ : C, 61.1\%; H, 4.6\%. Found, C, 61.0\% H, $4.3 \%$.

$[\mathrm{Fe}(\mathrm{CO})(\mathrm{dppe}) \mathrm{Cp}]\left[\mathrm{BPh}_{4}\right]$ A mixture of $\left[\mathrm{FeI}(\mathrm{CO})_{2} \mathrm{Cp}\right](0.43 \mathrm{~g}, 1.41 \mathrm{mmol})$, diphenylphosphinoethane $(0.56 \mathrm{~g}, 1.41 \mathrm{mmol})$ and sodium tetraphenylborate $(0.96 \mathrm{~g}$, $2.81 \mathrm{mmol})$ in toluene $(50 \mathrm{~mL})$ was heated at reflux with stirring for $18 \mathrm{~h}$ resulting in the formation of a yellow-brown precipitate. The reaction mixture was cooled and the precipitate was collected. Recrystallization from dichloromethane/diethyl ether gave the product in $61 \%$ yield as a yellow solid $(0.74 \mathrm{~g}, 0.85 \mathrm{mmol}) .{ }^{1} \mathrm{H} \mathrm{NMR}\left(\mathrm{CDCl}_{3}\right): \delta$ 2.04, 2.19 (br, 4H, $\mathrm{CH}_{2}$, dppe), 4.40 (s, 5H, Cp), 6.71, 6.84, 6.95, 7.18, 7.32, 7.43 (m, $40 \mathrm{H}, \mathrm{Ph}, \mathrm{dppe}) .{ }^{31} \mathrm{P}\left\{{ }^{1} \mathrm{H}\right\}$ NMR $\left(\mathrm{CDCl}_{3}\right): \delta$ 92.9. FT-IR $\left(\mathrm{CH}_{2} \mathrm{Cl}_{2}\right) v 1979$ (ATR) $v$ $1970 \mathrm{~cm}^{-1}(\mathrm{C} \equiv \mathrm{O})$. MALDI/MS $(\mathrm{m} / z): 547[\mathrm{M}]^{+}$. Anal.: Calcd. (\%) for $\mathrm{C}_{56} \mathrm{H}_{49} \mathrm{FeP}_{2} \mathrm{OB}$ : C, 77.6\%; H, 5.7\%. Found, C, 77.2\% H, 5.6\%.

\section{Computational Details}

All structure optimizations and property calculations used the TURBOMOLE program (versions $6.4^{60}$ and $7.1,^{61}$ locally modified by the Berlin group). The COSMO continuum solvent model for dichloromethane (DCM, $\varepsilon=8.93)^{62}$ was

generally applied, using non-equilibrium solvation in TDDFT calculations. ${ }^{62-63}$ Due to the involvement of the solvent model, vibrational frequency calculations were done by numerical differentiation of analytical gradients using TURBOMOLE's NumForce script (SCF convergence $10^{-8} \mathrm{E}_{\mathrm{h}}$ ). The resulting harmonic vibrational frequencies were scaled by an empirical factor of $0.895 .^{43}$

All structure optimizations and vibrational frequency analyses were carried out with the BLYP35 functional, ${ }^{41}$ a global hybrid based on B88 exchange and LYP correlation (BLYP functional) ${ }^{64-65}$ using 35\% exact-exchange admixture. BLYP35 has been found to perform well for mixed-valence (MV) systems near the Class II/III borderline in the Robin-Day scheme. ${ }^{14,41-42,51,66}$ Additional structure optimizations and vibrational frequency calculations were performed with the well-known global hybrid functional B3LYP, ${ }^{65,67-69}$ using the full ligand sphere, solvent model and dispersion correction to provide comparison with the results from earlier gas-phase 
calculations on truncated models of $[\mathbf{1 b}]^{+}$(substituting phenyl moieties of the dppe ligands with hydrogen atoms). ${ }^{24}$

Due to the observation of appreciable spin contamination and poor reproduction of the excitation energies for the present iron complexes using BLYP35, additional single-point calculations of ground-state energies and TDDFT calculations of excitation spectra used the Lh-SsirPW92 local hybrid functional with positiondependent exact-exchange admixture and a partially self-interaction-corrected correlation part. ${ }^{44}$ The local hybrid functional is constructed according to

$$
\begin{aligned}
E_{\mathrm{X}}^{L h} & =\int a(\mathbf{r}) \varepsilon_{\mathrm{X}}^{\text {exact }}(\mathbf{r}) \mathrm{d} \mathbf{r} \\
& +\int[1-a(\mathbf{r})] \varepsilon_{\mathrm{X}}^{\mathrm{DFT}}(\mathbf{r}) \mathrm{d} \mathbf{r}+E_{\mathrm{C}}^{\mathrm{DFT}}
\end{aligned}
$$

where the constant admixture parameter $a$ (global hybrid functional, e.g. 0.35 for BLYP35, 0.2 for B3LYP) has been replaced by a real-space dependent local mixing function $a(\mathbf{r})$ :

$$
a(\mathbf{r})=0.646 \tau_{\mathrm{W}} / \tau,
$$

where $\tau_{\mathrm{W}}$ and $\tau$ are the von Weizsäcker and the Kohn-Sham kinetic-energy densities, respectively.

This and closely related local hybrids have not only been found to perform extremely well in TDDFT calculations of a wide range of excitation classes, ${ }^{70}$ but such functionals also have interesting properties regarding the treatment of mixed-valence systems, ${ }^{47}$ thus extending our general computational protocol. The calculations used the recent efficient semi-numerical implementation of local hybrids into TURBOMOLE $7.1^{61}$

for ground $-^{45}$ and TDDFT excited-state ${ }^{46}$ calculations (in the latter case extending the available Turbomole TDDFT implementation ${ }^{71}$ ).

In general, def2-SVP basis sets were used. ${ }^{72}$ Earlier calculations on the ruthenium complexes using larger basis sets (def2-TZVP) gave negligible changes in structure and spectroscopic parameters. ${ }^{16}$ Numerical integration grids of size $\mathrm{m} 3$ (grid 1 for the SCF iterations, grid 3 for the final energy evaluation) were applied. Semi-empirical 
dispersion correction terms within Grimme's DFT-D3 approach have been added, ${ }^{73}$ using DFT-D3 parameters $\mathrm{rs}_{6}=1.1225$ and $\mathrm{s}_{8}=0.9258$ optimized for the BLYP35 functional ${ }^{74}$ and $\mathrm{rs}_{6}=0.77$ and $\mathrm{s}_{8}=1.429$ for the Lh-SsirPW92 functional. ${ }^{75}$

A relaxed scan was performed (BLYP35-D3) for computationally less demanding compound $[\mathbf{1 b}]^{+}$, evaluating the potential-energy surface along different $\mathrm{P}-\mathrm{Fe}-\ldots-\mathrm{Fe}-\mathrm{P}$ torsional angles $(\Omega)$ in steps of $10^{\circ}$. Unconstrained structure optimizations of the minima obtained during the scan were then done. Similar relaxed scans for [2a,b] have been taken from our previous work. ${ }^{14,16}$ Molecular-orbital and spin-density isosurface plots were obtained with the MOLEKEL software package. ${ }^{76}$ For $[1 \mathbf{a}]^{+}$, seven starting structures with torsional angles taken from $[\mathbf{2 a}]^{+}$were used to investigate its potential energy surface (PES).

\section{Associated Content}

Supporting Information Available: The Supporting Information is available free of charge on the ACS Publications website at DOI: XXXXXXXX.

- Plot of the molecular structure of $\mathbf{1 b}$ and summary of crystal data

- Plot of the cyclic voltammogram of $\mathbf{1 b}$

- Plots of the IR spectra of $\left[\left\{\mathrm{Fe}(\text { dppe }) \mathrm{Cp}^{*}\right\}_{2}(\mu-\mathrm{C} \equiv \mathrm{C}-\mathrm{C} \equiv \mathrm{C})\right]^{\mathrm{n}+}\left([\mathbf{1} \mathbf{a}]^{\mathrm{n}+}\right)(\mathrm{n}=0-2)$

- Tabulated $v\left(\mathrm{C} \equiv \mathrm{C}\right.$ ) data (from $\mathrm{CH}_{2} \mathrm{Cl}_{2}$ solutions) from selected complexes $\left[\left\{\mathrm{L}_{\mathrm{m}} \mathrm{M}\right\}(\mu-\mathrm{C} \equiv \mathrm{CC} \equiv \mathrm{C})\left\{\mathrm{ML}_{\mathrm{m}}\right\}\right]^{\mathrm{n}+}$

- Plot comparing the solid and solution state spectra of $[\mathbf{1 a}]^{+}$and $[\mathbf{1 b}]^{+}$

- Plots of the relative energies (BLYP35-D3/def2-SVP) of various conformers of $[\mathbf{1 b}]^{+},[\mathbf{2 a}]^{+}$and $[\mathbf{2 b}]^{+}$ 
- Tabulated computed structural properties of all minima at BLYP35-D3 level, and those for $[\mathbf{1 a}]^{+}$and $[\mathbf{1 b}]^{+}$at B3LYP-D3 level,

- Tabulated Mulliken spin densities and associated plots

- Tabuated molecular orbital populations and associated plots

- Tabulated excitation energies and tranistion dipole moments

- Plots of experimental NIR spectra of $[\mathbf{1 a}]^{+}$and $[\mathbf{1 b}]^{+}$overlayed with convoluted Gaussian broadened (line width: $800 \mathrm{~cm}^{-1}$ ) stick spectra from Lh-SsirPW92-D3 and BLYP35-D3 calculated spectra.

- Tabulated transition character of electronic excitations of different conformers at Lh-SsirPW92-D3 level of theory

- Tabulated relative energies $\left(\mathrm{kJ} \mathrm{mol}^{-1}\right)$, total spin expectation values, and computed harmonic vibrational frequencies for different conformers of $[\mathbf{1 a}]^{+}$and $[\mathbf{1 b}]^{+}$at B3LYP-D3/def2-SVP level of theory

\section{Accession Codes}

CCDC 1570320 contains the supplementary crystallographic data for this paper. These data can be obtained free of charge via www.ccdc.cam.ac.uk/data_request/cif, or by emailing data_request@ccdc.cam.ac.uk, or by contacting The Cambridge Crystallographic Data Centre, 12, Union Road, Cambridge CB2 1EZ, UK; fax: +44 1223336033.

\section{Notes}

The authors declare no competing financial interest.

Acknowledgment. This research was supported by the ARC (DP 140100855) and DFG (KA1187/13-2). P.J.L. held an ARC Future Fellowship (FT 120100073) and holds a Friedrich Wilhelm Bessel Research Award from the Alexander von Humboldt Foundation. This project was further supported by the North-German Supercomputing Alliance (HLRN), which provided HPC resources for numerical frequency calculations. We thank the Government of Libya for a research studentship (to S. E.T.) and the DAAD/Go8 for a travel grant which has enhanced the collaboration between Perth and Berlin. We are also grateful to Mr. Damien Bainbridge for the construction of spectroscopy cell holders, which greatly facilitated the spectroelectrochemical measurements. 


\section{References}

1. Bruce, M. I.; Low, P. J., Transition metal complexes containing all-carbon ligands. Adv Organomet Chem 2004, 50, 179-444.

2. Lenarvor, N.; Lapinte, C., 1 st $\mathrm{C}_{4}$ Bridged Mixed-Valence Iron(II)-Iron(III) Complex Delocalized on the Infrared Timescale. J Chem Soc Chem Comm 1993, (4), 357-359.

3. Lenarvor, N.; Toupet, L.; Lapinte, C., Elemental Carbon-Chain Bridging 2 Iron Centers - Syntheses and Spectroscopic Properties of [Cp*(dppe)Fe- $\mathrm{C}_{4}$ FeCp* (dppe) $]^{\mathrm{n}+\bullet}\left[\left[\mathrm{PF}_{6}\right]^{-}\right.$. X-Ray Crystal-Structure of the Mixed-Valence Complex (n=1). J Am Chem Soc 1995, 117 (27), 7129-7138.

4. Guillemot, M.; Toupet, L.; Lapinte, C., A four-oxidation-state family of coordinated carbon: The first isolable and crystallographically characterized triradical [M]-C $4-[\mathrm{M}]^{3+}$. Organometallics 1998, 17 (10), 1928-1930.

5. Halet, J. F.; Lapinte, C., Charge delocalization vs localization in carbon-rich iron mixed-valence complexes: A subtle interplay between the carbon spacer and the (dppe)Cp*Fe organometallic electrophore. Coord Chem Rev 2013, 257 (9-10), 1584-1613.

6. Brady, M.; Weng, W. Q.; Zhou, Y. L.; Seyler, J. W.; Amoroso, A. J.; Arif, A. M.; Bohme, M.; Frenking, G.; Gladysz, J. A., Consanguineous families of coordinated carbon: A ReC4Re assembly that is isolable in three oxidation states, including crystallographically characterized $\mathrm{ReC} \equiv \mathrm{CC} \equiv \mathrm{CRe}$ and ${ }^{+} \mathrm{Re}=\mathrm{C}=\mathrm{C}=\mathrm{C}=\mathrm{C}=\mathrm{Re}^{+}$adducts and a radical cation in which charge is delocalized between rhenium termini. J Am Chem Soc 1997, 119 (4), 775-788.

7. Jiao, H. J.; Costuas, K.; Gladysz, J. A.; Halet, J. F.; Guillemot, M.; Toupet, L.; Paul, F.; Lapinte, C., Bonding and electronic structure in consanguineous and conjugal iron and rhenium sp carbon chain complexes $\left[\mathrm{MC}_{4} \mathrm{M}^{\prime}\right]^{\mathrm{n}+}$ :

Computational analyses of the effect of the metal. J Am Chem Soc 2003, 125 (31), 9511-9522.

8. Bruce, M. I.; Denisovich, L. I.; Low, P. J.; Peregudova, S. M.; Ustynuk, N. A., Five oxidation states in metal-bonded $\mathrm{C}_{4}$ chains. Mendeleev Commun 1996, (5), 200-201.

9. Bruce, M. I.; Low, P. J.; Costuas, K.; Halet, J. F.; Best, S. P.; Heath, G. A., Oxidation chemistry of metal-bonded C-4 chains: A combined chemical, spectroelectrochemical, and computational study. J Am Chem Soc 2000, 122 (9), 1949-1962.

10. Bruce, M. I.; Ellis, B. G.; Low, P. J.; Skelton, B. W.; White, A. H., Syntheses, structures, and spectro-electrochemistry of

$\{\mathrm{Cp} *(\mathrm{PP}) \mathrm{Ru}\} \mathrm{C} \equiv \mathrm{CC} \equiv \mathrm{C}\left\{\mathrm{Ru}(\mathrm{PP}) \mathrm{Cp}^{*}\right\}(\mathrm{PP}=\mathrm{dppm}$, dppe $)$ and their mono- and dicationst. Organometallics 2003, 22 (16), 3184-3198.

11. Bruce, M. I.; Costuas, K.; Davin, T.; Ellis, B. G.; Halet, J. F.; Lapinte, C.; Low, P. J.; Smith, M. E.; Skelton, B. W.; Toupet, L.; White, A. H., Iron versus ruthenium: Dramatic changes in electronic structure result from replacement 
of one $\mathrm{Fe}$ by $\mathrm{Ru}$ in $\left[\{\mathrm{Cp} *(\mathrm{dppe}) \mathrm{Fe}\}-\mathrm{CC}-\mathrm{CC}-\left\{\mathrm{Fe}(\mathrm{dppe}) \mathrm{Cp}^{*}\right\}\right]^{\mathrm{n+}}(\mathrm{n}=0,1,2)$. Organometallics 2005, 24 (16), 3864-3881.

12. Bruce, M. I.; Kramarczuk, K. A.; Skelton, B. W.; White, A. H., Syntheses, structures and redox properties of $\left\{\mathrm{Os}\left(\mathrm{PPh}_{3}\right)_{2} \mathrm{Cp}\right\}_{2}\left\{\mu-(\mathrm{C} \equiv \mathrm{C})_{\mathrm{x}}\right\}(\mathrm{x}=2,3,4)$ : Comparisons with the Ru analogues. J Organomet Chem 2010, 695 (3), 469473.

13. Bruce, M. I.; Le Guennic, B.; Scoleri, N.; Zaitseva, N. N.; Halet, J. F., Extending Metal-Capped Polyynediyl Molecular Wires by Insertion of Inorganic Metal Units. Organometallics 2012, 31 (13), 4701-4706.

14. Parthey, M.; Gluyas, J. B. G.; Schauer, P. A.; Yufit, D. S.; Howard, J. A. K.; Kaupp, M.; Low, P. J., Refining the Interpretation of Near-Infrared Band Shapes in a Polyynediyl Molecular Wire. Chem-Eur J 2013, 19 (30), 97809784.

15. Gluyas, J. B. G.; Sobolev, A. N.; Moore, E. G.; Low, P. J., Broad-Band NIR Transient Absorption Spectroscopy of an "All-Carbon"-Bridged Bimetallic Radical Cation Complex. Organometallics 2015, 34 (16), 3923-3926.

16. Gluyas, J. B. G.; Guckel, S.; Kaupp, M.; Low, P. J., Rational Control of Conformational Distributions and Mixed-Valence Characteristics in Diruthenium Complexes. Chem-Eur J 2016, 22 (45), 16138-16146.

17. Venkatesan, K.; Fox, T.; Schmalle, H. W.; Berke, H., Synthesis and characterization of redox-active $\mathrm{C}_{4}$-bridged rigid-rod complexes with acetylide-substituted manganese end groups. Organometallics 2005, 24 (12), 2834-2847.

18. Venkatesan, K.; Blacque, O.; Berke, H., Organometallic manganese complexes as scaffolds for potential molecular wires. Dalton Trans 2007, (11), 1091-1100.

19. Fritz, T.; Schmalle, H. W.; Blacque, O.; Venkatesan, K.; Berke, H., Synthesis and Charactertzation of Mononuclear and Dinuclear Manganese Bis-acetylide Complexes. Z Anorg Allg Chem 2009, 635 (9-10), 1391-1401.

20. Semenov, S. N.; Taghipourian, S. F.; Blacque, O.; Fox, T.; Venkatesan, K.; Berke, H., An Iron-Capped Metal-Organic Polyyne: $\left\{[\mathrm{Fe}](\mathrm{C} \equiv \mathrm{C})_{2}[\mathrm{~W}] \mathrm{C} \equiv \mathrm{CC} \equiv \mathrm{C}[\mathrm{W}](\mathrm{C} \equiv \mathrm{C})_{2}[\mathrm{Fe}]\right\} . J$ Am Chem Soc 2010, 132 (22), 7584-7585.

21. Lissel, F.; Schwarz, F.; Blacque, O.; Riel, H.; Lortscher, E.; Venkatesan, K.; Berke, H., Organometallic Single-Molecule Electronics: Tuning Electron Transport through $\mathrm{X}$ (diphosphine) ${ }_{2} \mathrm{FeC}_{4} \mathrm{Fe}$ (diphosphine) ${ }_{2} \mathrm{X}$ Building Blocks by Varying the Fe-X-Au Anchoring Scheme from Coordinative to Covalent. $J$ Am Chem Soc 2014, 136 (41), 14560-14569.

22. Fitzgerald, E. C.; Brown, N. J.; Edge, R.; Helliwell, M.; Roberts, H. N.; Tuna, F.; Beeby, A.; Collison, D.; Low, P. J.; Whiteley, M. W., Orbital Symmetry Control of Electronic Coupling in a Symmetrical, All-Carbon-Bridged "Mixed Valence" Compound: Synthesis, Spectroscopy, and Electronic Structure of $\left[\left\{\mathrm{Mo}(\mathrm{dppe})\left(\eta-\mathrm{C}_{7} \mathrm{H}_{7}\right)\right\}_{2}\left(\mu-\mathrm{C}_{4}\right)\right]^{\mathrm{n}+}(\mathrm{n}=0,1$, or 2$)$. Organometallics 2012, 31 (1), 157-169.

23. Herrmann, C.; Neugebauer, J.; Gladysz, J. A.; Reiher, M., Theoretical study on the spin-state energy splittings and local spin in cationic $[\mathrm{Re}]-\mathrm{C}_{\mathrm{n}}-[\mathrm{Re}]$ complexes. Inorg Chem 2005, 44 (18), 6174-6182.

24. Coat, F.; Paul, F.; Lapinte, C.; Toupet, L.; Costuas, K.; Halet, J. F., Chemistry of the 1,3,5,7-octatetraynediyl carbon rod end-capped by two electron-rich $\left(\eta^{5}-\mathrm{C}_{5} \mathrm{Me}_{5}\right)\left(\eta^{2}\right.$-dppe)Fe groups. J Organomet Chem 2003, 683 (2), 368-378. 
25. Beddoes, R. L.; Bitcon, C.; Ricalton, A.; Whiteley, M. W., Ligand-Centered Coupling of the Alkynyl Radical Cations $\left[\mathrm{Mo}(\mathrm{C} \equiv \mathrm{CR})\left(\mathrm{Ph}_{2} \mathrm{PCH}_{2} \mathrm{CH}_{2} \mathrm{PPh}_{2}\right)(\eta\right.$ $\left.\left.\mathrm{C}_{7} \mathrm{H}_{7}\right)\right]^{+}\left(\mathrm{R}=\mathrm{Ph}\right.$ or $\left.\mathrm{Bu}^{\mathrm{n}}\right)$. Crystal-Structure of the Dimeric Product $\left[\mathrm{Mo}_{2}\left(\mathrm{Ph}_{2} \mathrm{PCH}_{2} \mathrm{CH}_{2} \mathrm{PPh}_{2}\right)_{2}\left(\eta-\mathrm{C}_{7} \mathrm{H}_{7}\right)_{2}\left(\mu-\mathrm{C}_{4} \mathrm{Ph}_{2}\right)\right]\left[\mathrm{PF}_{6}\right]_{2}$. J Organomet Chem 1989, 367 (3), C21-C24.

26. Szafert, S.; Gladysz, J. A., Update 1 of: Carbon in one dimension: Structural analysis of the higher conjugated polyynes. Chem Rev 2006, 106 (11), PR1PR33.

27. Szafert, S.; Gladysz, J. A., Carbon in one dimension: Structural analysis of the higher conjugated polyynes. Chem Rev 2003, 103 (11), 4175-4205.

28. Bruce, M. I.; Hall, B. C.; Kelly, B. D.; Low, P. J.; Skelton, B. W.; White, A. H., An efficient synthesis of polyynyl and polyynediyl complexes of ruthenium(II). J Chem Soc Dalton Trans 1999, (21), 3719-3728.

29. Bruce, M. I.; Ellis, B. G.; Gaudio, M.; Lapinte, C.; Melino, G.; Paul, F.; Skelton, B. W.; Smith, M. E.; Toupet, L.; White, A. H., Preparation, structures and some reactions of novel diynyl complexes of iron and ruthenium. Dalton Trans 2004, (10), 1601-1609.

30. Bruce, M. I.; Cole, M. L.; Costuas, K.; Ellis, B. G.; Kramarczuk, K. A.; Lapinte, C.; Nicholson, B. K.; Perkins, G. J.; Skelton, B. W.; White, A. H.; Zaitseva, N. N., Syntheses and Structural Studies of Several Group 8 Metal Complexes Derived from 1,3-Butadiyne. Z Anorg Allg Chem 2013, 639 (1213), 2216-2223.

31. Catheline, D.; Astruc, D., Piano-Stool (Pentamethylcyclopentadienyl)Iron Complexes - Syntheses and Simple Coordination Chemistry. Organometallics 1984, 3 (7), 1094-1100.

32. Riley, P. E.; Davis, R. E., Structure and Bonding in Neutral and Cationic Iron Carbonyl Phosphine Complexes - the Crystal-Structures of $(\pi-$ $\left.\mathrm{C}_{8} \mathrm{H}_{6}\right) \mathrm{Fe}(\mathrm{CO})_{2}\left(\mathrm{PPh}_{3}\right),\left[\left(\pi-\mathrm{C}_{5} \mathrm{H}_{5}\right) \mathrm{Fe}(\mathrm{CO})_{2}\left(\mathrm{PPh}_{3}\right)\right] \mathrm{Cl} \cdot 3 \mathrm{H}_{2} \mathrm{O}$, and $[(\pi-$ $\left.\left.\mathrm{C}_{5} \mathrm{H}_{5}\right) \mathrm{Fe}(\mathrm{CO})\left(\mathrm{Ph} 2 \mathrm{PCH}_{2} \mathrm{CH}_{2} \mathrm{PPh}_{2}\right)\right] \mathrm{BF}_{4}$. Organometallics 1983, 2 (2), 286-292.

33. Paul, F.; Toupet, L.; Roisnel, T.; Hamon, P.; Lapinte, C., Solid-state characterisation of the $\left[\left(\eta^{2}-\mathrm{dppe}\right)\left(\eta^{5}-\mathrm{C}_{5} \mathrm{Me}_{5}\right) \mathrm{FeCO}\right]^{+}$cation: an unexpected 'oxidation' product of the $\left[\left(\eta^{2} \text {-dppe }\right)\left(\eta^{5}-\mathrm{C}_{5} \mathrm{Me}_{5}\right) \mathrm{FeC} \equiv \mathrm{C}\left(\mathrm{C}_{6} \mathrm{H}_{4}\right) \mathrm{NMe}_{2}\right]^{2+}$ radical cation. C R Chim 2005, 8 (8), 1174-1185.

34. Krejcik, M.; Danek, M.; Hartl, F., Simple Construction of an Infrared Optically Transparent Thin-Layer Electrochemical-Cell - Applications to the Redox Reactions of Ferrocene, $\mathrm{Mn}_{2}(\mathrm{CO})_{10}$ and $\mathrm{Mn}(\mathrm{CO})_{3}(3,5$-Di-tert-ButylCatecholate)-. J Electroanal Chem 1991, 317 (1-2), 179-187.

35. Lapinte, C., Magnetic perturbation of the redox potentials of localized and delocalized mixed-valence complexes. J Organomet Chem 2008, 693 (5), 793801.

36. Winter, R. F., Half-Wave Potential Splittings $\Delta \mathrm{E}_{1 / 2}$ as a Measure of Electronic Coupling in Mixed-Valent Systems: Triumphs and Defeats. Organometallics 2014, 33 (18), 4517-4536.

37. D'Alessandro, D. M.; Keene, F. R., A cautionary warning on the use of electrochemical measurements to calculate comproportionation constants for mixed-valence compounds. Dalton Trans 2004, (23), 3950-3954.

38. Low, P. J.; Brown, N. J., Electronic Interactions Between and Through Covalently-Bonded Polymetallic Complexes. J Clust Sci 2010, 21 (3), 235 278. 
39. Renz, M.; Kess, M.; Diedenhofen, M.; Klamt, A.; Kaupp, M., Reliable Quantum Chemical Prediction of the Localized/Delocalized Character of Organic Mixed-Valence Radical Anions. From Continuum Solvent Models to Direct-COSMO-RS. J Chem Theory Comput 2012, 8 (11), 4189-4203.

40. Renz, M.; Kaupp, M., Predicting the Localized/Delocalized Character of Mixed-Valence Diquinone Radical Anions. Toward the Right Answer for the Right Reason. J Phys Chem A 2012, 116 (43), 10629-10637.

41. Renz, M.; Theilacker, K.; Lambert, C.; Kaupp, M., A Reliable QuantumChemical Protocol for the Characterization of Organic Mixed-Valence Compounds. J Am Chem Soc 2009, 131 (44), 16292-16302.

42. Parthey, M.; Kaupp, M., Quantum-chemical insights into mixed-valence systems: within and beyond the Robin-Day scheme. Chem Soc Rev 2014, 43 (14), 5067-5088.

43. Scott, A. P.; Radom, L., Harmonic vibrational frequencies: An evaluation of Hartree-Fock, Moller-Plesset, quadratic configuration interaction, density functional theory, and semiempirical scale factors. J Phys Chem-Us 1996, 100 (41), 16502-16513.

44. Arbuznikov, A. V.; Kaupp, M., Importance of the correlation contribution for local hybrid functionals: Range separation and self-interaction corrections. $J$ Chem Phys 2012, 136 (1).

45. Bahmann, H.; Kaupp, M., Efficient Self-Consistent Implementation of Local Hybrid Functionals. J Chem Theory Comput 2015, 11 (4), 1540-1548.

46. Maier, T. M.; Bahmann, H.; Kaupp, M., Efficient Semi-numerical Implementation of Global and Local Hybrid Functionals for Time-Dependent Density Functional Theory. J Chem Theory Comput 2015, 11 (9), 4226-4237.

47. Kaupp, M.; Karton, A.; Bischoff, F. A., $\left[\mathrm{Al}_{2} \mathrm{O}_{4}\right]^{\text {, a }}$ a Benchmark Gas-Phase Class II Mixed-Valence Radical Anion for the Evaluation of QuantumChemical Methods. J Chem Theory Comput 2016, 12 (8), 3796-3806.

48. Klawohn, S.; Bahmann, H.; Kaupp, M., Implementation of Molecular Gradients for Local Hybrid Density Functionals Using Seminumerical Integration Techniques. J Chem Theory Comput 2016, 12 (9), 4254-4262.

49. Ito, T.; Hamaguchi, T.; Nagino, H.; Yamaguchi, T.; Kido, H.; Zavarine, I. S.; Richmond, T.; Washington, J.; Kubiak, C. P., Electron transfer on the infrared vibrational time scale in-the mixed valence state of 1,4-pyrazine- and 4,4 'bipyridine-bridged ruthenium cluster complexes. J Am Chem Soc 1999, 121 (19), 4625-4632.

50. Ito, T.; Hamaguchi, T.; Nagino, H.; Yamaguchi, T.; Washington, J.; Kubiak, C. P., Effects of rapid intramolecular electron transfer on vibrational spectra. Science 1997, 277 (5326), 660-663.

51. Kaupp, M.; Renz, M.; Parthey, M.; Stolte, M.; Wurthner, F.; Lambert, C., Computational and spectroscopic studies of organic mixed-valence compounds: where is the charge? Phys Chem Chem Phys 2011, 13 (38), 16973-16986.

52. Demadis, K. D.; Hartshorn, C. M.; Meyer, T. J., The localized-to-delocalized transition in mixed-valence chemistry. Chem Rev 2001, 101 (9), 2655-2685.

53. Kaupp, M., The role of radial nodes of atomic orbitals for chemical bonding and the periodic table. J Comput Chem 2007, 28 (1), 320-325.

54. El-Tarhuni, S.; Ho, M.; Kawser, M. H.; Shi, S. Q.; Whiteley, M. W., Synthesis and solvent induced halide exchange of the electron rich, half sandwich 
complexes $[\mathrm{FeI}(\mathrm{dppe}) \mathrm{Cp}]$ and $\left[\mathrm{MoX}(\mathrm{dppe})\left(\eta^{7}-\mathrm{C}_{7} \mathrm{H}_{7}\right)\right](\mathrm{X}=\mathrm{Br}, \mathrm{Cl}$; dppe $=$ $\mathrm{Ph}_{2} \mathrm{PCH}_{2} \mathrm{CH}_{2} \mathrm{PPh}_{2}$ ). J Organomet Chem 2014, 752, 30-36.

55. Gluyas, J. B. G.; Brown, N. J.; Farmer, J. D.; Low, P. J., Optimised Syntheses of the Half-Sandwich Complexes $\mathrm{FeCl}(d p p e) C p^{*}, \mathrm{FeCl}(\mathrm{dppe}) \mathrm{Cp}$, $\mathrm{RuCl}(\mathrm{dppe}) \mathrm{Cp}^{*}$, and $\mathrm{RuCl}(\mathrm{dppe}) \mathrm{Cp}$. Aust J Chem 2017, 70 (1), 113-119.

56. Fulmer, G. R.; Miller, A. J. M.; Sherden, N. H.; Gottlieb, H. E.; Nudelman, A.; Stoltz, B. M.; Bercaw, J. E.; Goldberg, K. I., NMR Chemical Shifts of Trace Impurities: Common Laboratory Solvents, Organics, and Gases in Deuterated Solvents Relevant to the Organometallic Chemist. Organometallics 2010, 29 (9), 2176-2179.

57. Gluyas, J. B. G.; Boden, A. J.; Eaves, S. G.; Yu, H.; Low, P. J., Long range charge transfer in trimetallic mixed-valence iron complexes mediated by redox non-innocent cyanoacetylide ligands. Dalton Trans 2014, 43 (17), 6291-6294.

58. Wang, Y. L.; Diallo, A. K.; Ornelas, C.; Ruiz, J.; Astruc, D., Visible-Light Generation of the Naked 12-Electron Fragment $\mathrm{C}_{5} \mathrm{H}_{5} \mathrm{Fe}^{+}$: Alkyne-toVinylidene Isomerization and Synthesis of Polynuclear Iron Vinylidene and Alkynyl Complexes Including Hexairon Stars. Inorg Chem 2012, 51 (1), 119127.

59. El-Tarhuni, S.; Manhaes, L. M.; Morrill, C.; Raftery, J.; Randhawa, J. K.; Whiteley, M. W., Synthesis of cyclopentadienyl iron alkoxycarbene complexes via vinylidene intermediates: $\mathrm{X}$-ray structures of $[\mathrm{Fe}\{\mathrm{C}(\mathrm{OMe}) \mathrm{Me}\}($ dppe $) \mathrm{Cp}][\mathrm{I}]$ and $\left[\mathrm{Fe}\left\{\mathrm{C}\left(\mathrm{CH}_{2}\right)_{3} \mathrm{O}\right\}(\right.$ dppe $\left.) \mathrm{Cp}\right][\mathrm{PF} 6] . J$ Organomet Chem 2016, 811, 20-25.

60. TURBOMOLE V6.4 2012, a development of the Univesrity of Karlsruhe and Forschungszentrum Karlsruhe GmbH, 1989-2007, TURBOMOLE GmbH, since 2007; available from http://www.turbomole.com.

61. TURBOMOLE V7.1 2016, a development of Univesrity of Karlsruhe and Forschungszentrum Kharlsruhe GmbH, 1989-2007, TURBOMOLE GmbH , since 2007; available from http://www.turbomole.com.

62. Klamt, A.; Schuurmann, G., Cosmo - a New Approach to Dielectric Screening in Solvents with Explicit Expressions for the Screening Energy and Its Gradient. J Chem Soc Perk T 2 1993, (5), 799-805.

63. Klamt, A., The COSMO and COSMO-RS solvation models. Wiley Interdiscipl Rev Comput Mol Sci 2011, 1 (5), 699-709.

64. Becke, A. D., Density-Functional Exchange-Energy Approximation with Correct Asymptotic-Behavior. Phys Rev A 1988, 38 (6), 3098-3100.

65. Lee, C. T.; Yang, W. T.; Parr, R. G., Development of the Colle-Salvetti Correlation-Energy Formula into a Functional of the Electron-Density. Phys Rev B 1988, 37 (2), 785-789.

66. Parthey, M.; Gluyas, J. B. G.; Fox, M. A.; Low, P. J.; Kaupp, M., MixedValence Ruthenium Complexes Rotating through a Conformational RobinDay Continuum. Chem-Eur J 2014, 20 (23), 6895-6908.

67. Becke, A. D., Density-Functional Thermochemistry .3. The Role of Exact Exchange. J Chem Phys 1993, 98 (7), 5648-5652.

68. Vosko, S. H.; Wilk, L.; Nusair, M., Accurate Spin-Dependent Electron Liquid Correlation Energies for Local Spin-Density Calculations - a Critical Analysis. Can J Phys 1980, 58 (8), 1200-1211.

69. Stephens, P. J.; Devlin, F. J.; Chabalowski, C. F.; Frisch, M. J., Ab-Initio Calculation of Vibrational Absorption and Circular-Dichroism Spectra Using 
Density-Functional Force-Fields. J Phys Chem-Us 1994, 98 (45), 11623 11627.

70. Maier, T. M.; Bahmann, H.; Arbuznikov, A. V.; Kaupp, M., Validation of local hybrid functionals for TDDFT calculations of electronic excitation energies. J Chem Phys 2016, 144 (7).

71. Bauernschmitt, R.; Haser, M.; Treutler, O.; Ahlrichs, R., Calculation of excitation energies within time-dependent density functional theory using auxiliary basis set expansions. Chem Phys Lett 1997, 264 (6), 573-578.

72. Weigend, F.; Ahlrichs, R., Balanced basis sets of split valence, triple zeta valence and quadruple zeta valence quality for $\mathrm{H}$ to $\mathrm{Rn}$ : Design and assessment of accuracy. Phys Chem Chem Phys 2005, 7 (18), 3297-3305.

73. Grimme, S.; Antony, J.; Ehrlich, S.; Krieg, H., A consistent and accurate ab initio parametrization of density functional dispersion correction (DFT-D) for the 94 elements H-Pu. J Chem Phys 2010, 132 (15).

74. Kaupp, M.; Guckel, S.; Renz, M.; Klawohn, S.; Theilacker, K.; Parthey, M.; Lambert, C., Electron Transfer Pathways in Mixed-Valence ParacyclophaneBridged Bis-Triarylamine Radical Cations. J Comput Chem 2016, 37 (1), 93102.

75. Theilacker, K.; Arbuznikov, A. V.; Kaupp, M., Gauge effects in local hybrid functionals evaluated for weak interactions and the GMTKN30 test set. $\mathrm{Mol}$ Phys 2016, 114 (7-8), 1118-1127.

76. Varetto, U., MOLEKEL 5.4. Swiss National COmputing Centre 2000. 